\title{
Enhancing Neuronal Plasticity and Cellular Resilience to Develop Novel, Improved Therapeutics for Difficult-to-Treat Depression
}

\author{
Husseini K. Manji, Jorge A. Quiroz, Jonathan Sporn, Jennifer L. Payne, \\ Kirk Denicoff, Neil A. Gray, Carlos A. Zarate Jr., and Dennis S. Charney
}

There is growing evidence from neuroimaging and postmortem studies that severe mood disorders, which have traditionally been conceptualized as neurochemical disorders, are associated with impairments of structural plasticity and cellular resilience. It is thus noteworthy that recent preclinical studies have shown that critical molecules in neurotrophic signaling cascades (most notably cyclic adenosine monophosphate [cAMP] response element binding protein, brain-derived neurotrophic factor, bcl-2, and mitogen activated protein [MAP] kinases) are long-term targets for antidepressant agents and antidepressant potentiating modalities. This suggests that effective treatments provide both trophic and neurochemical support, which serves to enhance and maintain normal synaptic connectivity, thereby allowing the chemical signal to reinstate the optimal functioning of critical circuits necessary for normal affective functioning. For many refractory patients, drugs mimicking "traditional" strategies, which directly or indirectly alter monoaminergic levels, may be of limited benefit. Newer "plasticity enhancing" strategies that may have utility in the treatment of refractory depression include $\mathrm{N}$-methyl-D-aspartate antagonists, alpha-amino-3-hydroxy-5-methylisoxazole propionate (AMPA) potentiators, cAMP phosphodiesterase inhibitors, and glucocorticoid receptor antagonists. Small-molecule agents that regulate the activity of growth factors, MAP kinases cascades, and the bcl-2 family of proteins are also promising future avenues. The development of novel, nonaminergic-based therapeutics holds much promise for improved treatment of severe, refractory mood disorders. Biol Psychiatry 2003;53:707-742 (C) 2003 Society of Biological Psychiatry

Key Words: Neuroplasticity, lithium, glutamate, brainderived neurotrophic factor, bcl-2, mitogen activated protein kinase

\footnotetext{
From the Laboratory of Molecular Pathophysiology (HKM, JAQ, JLP, KD, NG, CAZ), Experimental Therapeutics and Pathophysiology Branch, Mood and Anxiety Program (JS, KD, DSC), National Institute of Mental Health, Bethesda, Maryland.

Address reprint requests to Husseini K. Manji, M.D., F.R.C.P.(C), National Institute of Mental Health, Laboratory of Molecular Pathophysiology, Building 49, Room B1EE16, 49 Convent Drive, MSC 4405, Bethesda, MD 20892-4405. Received August 7, 2002; revised January 6, 2003; accepted January 23, 2003.
}

\section{Introduction}

7 espite the devastating impact that mood disorders have on the lives of millions worldwide, there is still a dearth of knowledge concerning their underlying etiology and pathophysiology. The brain systems that have heretofore received the greatest attention in neurobiologic studies of mood disorders have been the monoaminergic neurotransmitter systems, which are extensively distributed throughout the network of limbic, striatal, and prefrontal cortical (PFC) neuronal circuits thought to support the behavioral and visceral manifestations of mood disorders (Drevets 2001; Manji et al 2001a; Nestler et al 2002). Thus, clinical studies over the past 40 years have attempted to uncover the specific defects in these neurotransmitter systems in mood disorders by using a variety of biochemical and neuroendocrine strategies.

Although such investigations have been heuristic over the years, they have been of limited value in elucidating the unique biology of mood disorders, which must include an understanding of the underlying basis for the predilection to episodic and often profound mood disturbance, which can become progressive over time. Thus, mood disorders likely arise from the complex interaction of multiple susceptibility (and protective) genes and environmental factors, and the phenotypic expression of these diseases includes not only episodic and often profound mood disturbance, but also a constellation of cognitive, motoric, autonomic, endocrine, and sleep/wake abnormalities. Furthermore, although most antidepressants exert their initial effects by increasing the intrasynaptic levels of serotonin and/or norepinephrine, their clinical antidepressant effects are only observed after chronic (days to weeks) administration, suggesting that a cascade of downstream effects are ultimately responsible for their therapeutic effects. These observations have led to the appreciation that although dysfunction within the monoaminergic neurotransmitter systems is likely to play important roles in mediating some facets of the pathophys- 
iology of mood disorders, they likely represent the downstream effects of other, more primary abnormalities (Manji and Lenox 2000; Payne et al 2003).

In addition to the growing appreciation that investigations into the pathophysiology of complex mood disorders have been excessively focused on monoaminergic systems, there has been a growing appreciation that progress in developing truly novel and improved antidepressant medications has consequently also been limited. The selective serotonin reuptake inhibitors (SSRIs), for example, have a better side effect profile for many patients and are easier for physicians to prescribe; however, these newer medications have essentially the same mechanism of action as the tricyclic antidepressants and, as a result, the efficacy of the newer agents and the range of depressed patients they treat are no better than the older medications. Moreover, today's treatments remain suboptimal for many patients afflicted with depressive syndromes, and they continue to suffer protracted illnesses.

A recognition of the clear need for better treatments and the lack of significant advances in our ability to develop novel, improved therapeutics for these devastating illnesses has led to the investigation of the putative roles of intracellular signaling cascades and nonaminergic systems in the pathophysiology and treatment of mood disorders. Consequently, recent evidence demonstrating that impairments of neuroplasticity and cellular resilience may underlie the pathophysiology of mood disorders, and that antidepressants and mood stabilizers exert major effects on signaling pathways that regulate neuroplasticity and cell survival, have generated considerable excitement among the clinical neuroscience community and are reshaping views about the neurobiological underpinnings of these disorders (D'Sa and Duman 2002; Manji et al 2000, 2001a; Nestler et al 2002; Young 2002).

"Neuroplasticity" subsumes diverse processes of vital importance by which the brain perceives, adapts to, and responds to a variety of internal and external stimuli. The manifestations of neuroplasticity in the adult central nervous system (CNS) have been characterized as including alterations of dendritic function, synaptic remodeling, long-term potentiation, axonal sprouting, neurite extension, synaptogenesis, and even neurogenesis (see Mesulam 1999 for an excellent overview). Although the potential relevance of neuroplastic events for the pathophysiology of psychiatric disorders has been articulated for some time, recent morphometric studies of the brain (both in vivo and postmortem) is beginning to lead to a fuller appreciation of the magnitude and nature of the neuroplastic events involved in the pathophysiology of mood disorders. In this article, we review these data and discuss their implications not only for changing existing conceptualizations regarding the pathophysiology of mood disorders, but also for the strategic development of improved therapeutics for difficult-to-treat depression.

\section{Evidence for Impairments of Structural Plasticity and Cellular Resilience in Mood Disorders}

Positron emission tomography imaging studies have revealed multiple abnormalities of regional cerebral blood flow and glucose metabolism in limbic and PFC structures in mood disorders. These abnormalities implicate limbicthalamic-cortical and limbic-cortical-striatal-pallidalthalamic circuits, involving the amygdala, orbital and medial PFC, and anatomically related parts of the striatum and thalamus in the pathophysiology of mood disorders. Interestingly, recent morphometric magnetic resonance imaging (MRI) and postmortem investigations have also demonstrated abnormalities of brain structure that persist independently of mood state and may contribute to the corresponding abnormalities of metabolic activity (discussed in Manji and Duman 2001; Manji et al 2001a).

Structural imaging studies have demonstrated reduced gray matter volumes in areas of the orbital and medial PFC, ventral striatum, and hippocampus, and enlargement of third ventricle of patients with mood-disordered relative to healthy control samples (Appendix 1) (reviewed in Beyer and Krishnan 2002; Drevets 2001; Strakowski et al 2002). Also consistent is the presence of white matter hyperintensities $(\mathrm{WMH})$ in the brains of elderly depressed patients and patients with bipolar disorder; these lesions may be associated with poor treatment response (Lenox et al 2002). There is a growing awareness of the genetic influences on WMH and their possible impact on neuropsychological functioning (Carmelli et al 2002), but WMH may have multiple causes, including cerebrovascular accidents, demyelination, loss of axons, dilated perivascular space, minute brain cysts, and necrosis (Lenox et al 2002). In this context, it is noteworthy that recent studies have used diffusion tensor imaging of brain tissue to study possible white matter tract disruption in mood disorders (Taylor et al 2001). This procedure measures the apparent diffusion coefficient (ADC), or isotropic diffusion, and anisotropy, or diffusion as influenced by tissue structure. These authors showed that WMH showed higher ADC and lower anisotropy than did normal regions, with gray matter showing similar trends. Together, these results support the contention that WMH damage the structure of brain tissue and likely disrupt the neuronal connectivity necessary for normal affective functioning. Although the cause of WMH in mood disorders is unknown, their presence-particularly in the brains of young bipolar patients-suggests importance in the pathophysiology of the disorder (Lenox et al 2002; Stoll et al 2000). 
Table 1. Postmortem Morphometric Brain Studies in Mood Disorders Demonstrating Cellular Atrophy and/or Loss

Reduced Volume/Cortical Thickness

- Cortical thickness rostral oribitofrontal cortex, MDD (Rajkowska et al 1999)

- Laminar cortical thickness in layers III, V, and VI in subgenual anterior cingulate cortex (area 24) in BPD (Bouras et al 2001)

- Volume of subgenual prefrontal cortex in familial MDD and BPD (Ongur et al 1998)

- Volumes of nucleus accumbens (left), basal ganglia (bilateral) in MDD and BPD (Baumann et al 1999)

- Para hippocampal cortex size (right) in suicide (Altshuler et al 1990)

Reduced Neuronal Size and/or Density

- Pyramidal neuronal density, layers III and V in dorsolateral prefrontal cortex in BPD and MDD (Rajkowska 2000a)

- Neuronal size in layer V $(-14 \%)$ and VI $(-18 \%)$ in prefrontal cortex (area 9) in BPD (Cotter et al 2002)

- Neuronal size in layer VI (-20\%) in prefrontal cortex (area 9) in MDD (Cotter et al 2002)

- Neuronal density and size in layer II-IV in rostral oribitofrontal cortex, in layer V/VI in caudal oribitofrontal cortex, and in supra and infra granular layers in dorsolateral prefrontal cortex, in MDD (Rajkowska et al 1999)

- Neuronal size in layer VI $(-23 \%)$ in anterior cingulate cortex in MDD (Cotter et al 2001)

- Neuronal density in layer III, V, and VI in subgenual anterior cingulate cortex (area 24) in BPD (Bouras et al 2001)

- Layer specific interneurons in anterior cingulate cortex in BPD and MDD (Vincent et al 1997)

- Nonpyramidal neuronal density in layer II $(-27 \%)$ in anterior cingulate cortex in BPD (Benes et al 2001)

- Nonpyramidal neurons density in the CA2-region in BPD (Benes et al 1998)

Reduced Glia

- Density/size of glia in dorsolateral prefrontal cortex and caudal oribito frontal cortex in MDD \& BPD-layer specific (Miguel-Hidalgo and Rajkowska 2002; Rajkowska et al 1999)

- Glial cell density in sublayer IIIc $(-19 \%)$ (and a trend to decrease in layer Va) in dorsolateral prefrontal cortex (area 9) in BPD (Selemon, unpublished data)

- Glial number in subgenual prefrontal cortex in familial MDD (-24\%) and BPD (-41\%) (Ongur et al 1998)

- Glial cell density in layer V $(-30 \%)$ in prefrontal cortex (area 9) in MDD (Cotter et al 2002)

- Glial cell density in layer VI $(-22 \%)$ in anterior cingulate cortex in MDD (Cotter et al 2001)

- Glial cell counts, glial density, and glia-to-neuron ratios in amygdala in MDD (Bowley et al 2002)

MDD, major depressive disorder; BPD, bipolar disorder. Modified and reproduced with permission from Manji and Duman 2001.

Complementary postmortem neuropathologic studies have shown abnormal reductions in cortex volume, glial cell counts, and/or neuron size in the subgenual PFC, orbital cortex, dorsal anterolateral PFC, amygdala, and in basal ganglia and dorsal raphe nuclei (reviewed in Cotter et al 2001; Manji and Duman 2001; Rajkowska 2002b) (Table 1). It is not known whether these deficits constitute developmental abnormalities that may confer vulnerability to abnormal mood episodes, compensatory changes to other pathogenic processes, or the sequelae of recurrent affective episodes per se. Understanding these issues will partly depend on experiments that delineate the onset of such abnormalities within the illness course and determine whether they antedate depressive episodes in individuals at high familial risk for mood disorders. Although there is not total reproducibility among either the neuroimaging or postmortem studies, the differences likely represent variations of experimental design (including medication effects; see below) and-as would be expected in heterogenous disorders such as mood disorders-in patient populations. Thus, research is required to understand whether more rigorously defined subtypes of depression, or mood disorders, are associated with any particular abnormality (Lenox et al 2002). Nevertheless, the marked reduction in glial cells in these regions has been particularly intriguing in view of the growing appreciation that glia play critical roles in regulating synaptic glutamate concentrations and CNS energy homeostasis, as well as in releasing trophic factors that participate in the development and maintenance of synaptic networks formed by neuronal and glial processes (Coyle and Schwarcz 2000; Haydon 2001; Ongur et al 1998; Rajkowska 2000b; Rajkowska et al 1999; Ullian et al 2001). Abnormalities of glial function could thus prove integral to the impairments of structural plasticity and overall pathophysiology of mood disorders.

\section{Stress and Glucocorticoids Modulate Neural Plasticity: Implications for Mood Disorders}

In developing hypotheses regarding the pathogenesis of these histopathologic changes in mood disorders, the alterations in cellular morphology resulting from various stressors have been the focus of considerable recent research (D'Sa and Duman 2002) (Figure 1). Thus, although mood disorders undoubtedly have a strong genetic basis, considerable evidence has shown that severe stressors are associated with a substantial increase in risk for the onset of mood disorders in susceptible individuals. Most studies of atrophy and survival of neurons in response to stress, as well as hormones of the hypothalamic-pituitary-adrenal (HPA) axis, have focused on the hippocampus. This is owing, in part, to the well-defined and easily studied neuronal populations of this limbic brain region, including the 
dentate gyrus granule cell layer, and the CA1 and CA3 pyramidal cell layers. These cell layers and their connections (mossy fiber pathway and Schaffer collateral) have also been used as cellular models of learning and memory (i.e., long-term potentiation). Another major reason that the hippocampus has been the focus of stress research is that the highest levels of glucocorticoid receptors (GRs) are expressed in this brain region (Lopez et al 1998); however, it is clear that stress and glucocorticoids also influence the survival and atrophy of neurons in other brain regions (e.g., PFC; see below) that have not yet been studied in the same detail as the hippocampus.

One of the most consistent effects of stress on cellular morphology is atrophy of hippocampal neurons (for reviews see McEwen 1999; Sapolsky 2000). This atrophy is observed in the CA3 pyramidal neurons but not in other hippocampal cell groups (i.e., CA1 pyramidal and dentate gyrus granule neurons). The stress-induced atrophy of CA3 neurons (i.e., decreased number and length of the apical dendritic branches), occurs after 2-3 weeks of exposure to restraint stress or more long-term social stress and has been observed in rodents and tree shrews (McEwen 1999; Sapolsky 2000). Atrophy of CA3 pyramidal neurons also occurs upon exposure to high levels of glucocorticoids, suggesting that activation of the HPA axis likely plays a major role in mediating the stress-induced atrophy (McEwen 1999; Sapolsky 1996, 2000). The hippocampus has a very high concentration of glutamate and expresses both type I (mineralocorticoid receptor; MR) and type II (glucocorticoid receptor; GR) corticosteroid receptors, though type II receptors may be relatively scarce in the hippocampus of primates (Patel et al 2000; Sanchez et al 2000) and more abundant in cortical regions. Type I receptor activation in the hippocampus (CA1) is associated with reduced calcium currents, whereas activation of type II receptors causes increased calcium currents and enhanced responses to excitatory amino acids. Very high levels of type II receptor activation markedly increases calcium currents and lead to increased $N$-methylD-aspartate (NMDA) receptor throughput that could predispose to neurotoxicity. Indeed, as we discuss in greater detail below, a growing body of data has implicated glutamatergic neurotransmission in stress-induced hippocampal atrophy and death (McEwen 1999; see Figure 1).

A cautionary note in the interpretation of the clinical studies is suggested by the results of the recent longitudinal studies undertaken to investigate the effects of earlylife stress and inherited variation in monkey hippocampal volumes (Lyons et al 2001). In these studies, paternal half-siblings raised apart from one another by different mothers in the absence of fathers were randomized to one of three postnatal conditions that disrupted diverse aspects

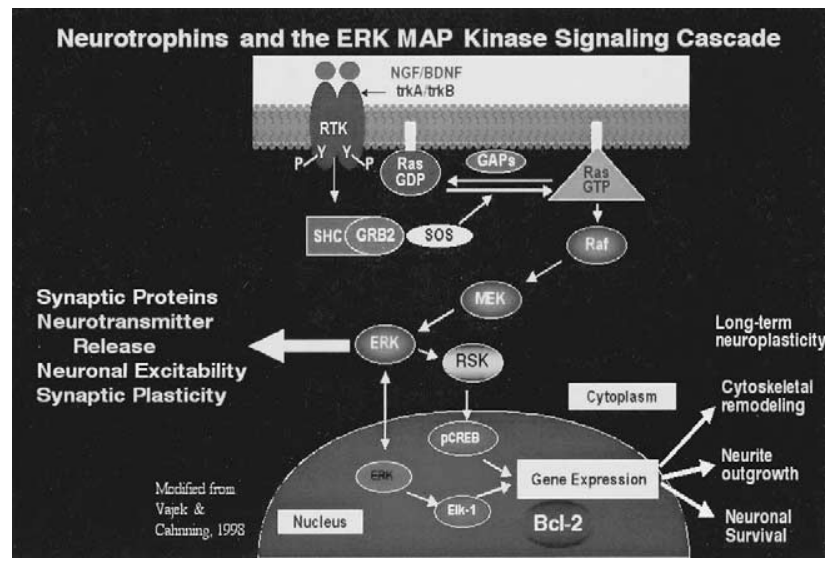

Figure 1. Neurotrophins and the ERK MAP kinase signaling cascade. Cell survival is dependent on neurotrophic factors, such as BDNF and NGF, and the expression of these factors can be induced by synaptic activity. The influence of neurotrophic factors on cell survival is mediated by activation of the MAP kinase cascade. Activation of neurotrophic factor receptors, also referred to as Trks, results in activation of the MAP kinase cascade via several intermediate steps, including phosphorylation of the adaptor protein SHC and recruitment of the guanine nucleotide exchange factor Sos. This results in activation of the small guanosine triphosphate-binding protein Ras, which leads to activation of a cascade of serine/threonine kinases. This includes Raf, MAP kinase kinase (MEK), and MAP kinase (also referred to as extracellular response kinase, or ERK). One target of the MAP kinase cascade is RSK, which influences cell survival in at least two ways. RSK phosphorylates and inactivates the pro-apoptotic factor BAD not shown in figure. Rsk also phosphorylates CREB and thereby increases the expression of the antiapoptotic factor $\mathrm{Bcl}-2$. These mechanisms underlie many of the long-term effects of neurotrophins, including neurite outgrowth, cytoskeletal remodeling, and cell survival. It is now clear, however, that BDNF also exerts many acute synaptic effects, including regulating the release of a number of neurotransmitters. MAP, mitogen-activated protein; BDNF, brainderived neurotrophic factor; NGF, nerve growth factor; CREB, cyclic adenosine monophosphate response element-binding protein; RTK, receptor tyrosine kinase; Y, tyrosine; P, phosphorylated; GDP, guanidine di-phosphate; GTP, guanidine tri-phosphate; GAP, GTPase activating proteins (also called RGS or regulators of $\mathrm{G}$ protein signaling proteins); GRB2, scaffolding protein that recognizes specific phosphotyrosine residues on the receptor; pCREB, phosphorylated CREB; Elk-1, promoter that increases transcription of neurotrophic genes.

of early maternal care. These researchers found that adult hippocampal volumes did not differ with respect to the stressful postnatal conditions but estimated that proportion of genetic variance (heritability) was 54\% for hippocampal size. Furthermore, paternal half-siblings with small adult hippocampal volumes responded to the removal of all mothers after weaning with initially larger relative 
increases in cortisol levels (Lyons et al 2001). Plasma cortisol levels 3 and 7 days later, and measures of cortisol-negative feedback in adulthood were not, however, correlated with hippocampal size. Thus, these studies suggest that small hippocampi also reflect an inherited characteristic of the brain and highlight the need for caution in attribution of causality in the cross-sectional human morphometric studies of the hippocampus.

Although not as extensively studied as the hippocampus, recent research has also demonstrated histopathologic changes in rat PFC after corticosterone administration (Wellman 2001). Thus, using a Golgi-Cox procedure, Wellman (2001) investigated pyramidal neurons in layer II-III of medial PFC, and quantified dendritic morphology in three dimensions. This study demonstrated a significant redistribution of apical dendrites in corticosterone-treated animals, with the amount of dendritic material proximal to the soma being increased and distal dendritic material being decreased. These findings suggest that stress may produce a significant reorganization of the apical dendritic arbor from medial PFC in rats. Most recently, Lyons (2002) demonstrated that 4 years after a brief stressor (intermittent postnatal separations from maternal availability) young adult squirrel monkeys showed significantly larger right ventral medial prefrontal volumes. Neither overall brain volumes nor left prefrontal measures were altered, suggesting selective (rather than nonspecific) effects. An intriguing observation of this study was that, similar to their hippocampal findings (see above), these investigators found a strong heritability of the right ventral medial prefrontal volume. Thus, in this study, certain fathers produced offspring with large right ventral medial prefrontal volumes, whereas others produced offspring with small right ventral medial prefrontal volumes (Lyons 2002). Because the paternal half-siblings were raised apart by different mothers in the absence of fathers, the phenotypic similarities in right ventral medial prefrontal volumes likely represent a major genetic contribution, effects which were not seen for other prefrontal regions (Lyons 2002).

\section{Mechanisms Underlying Stress-Induced Morphometric Changes}

Microdialysis studies have shown that stress increases extracellular levels of glutamate in hippocampus, and NMDA glutamate receptor antagonists attenuate stressinduced atrophy of CA3 pyramidal neurons (McEwen 1999; Sapolsky 2000). Although a variety of methodologic issues remain to be fully resolved, the preponderence of the evidence to date suggests that the atrophy, and possibly death, of CA3 pyramidal neurons arises, at least in part, from increased glutamate neurotransmission (McEwen 1999; Sapolsky 2000). It should be noted, however, that although NMDA antagonists block stress-induced hippocampal atrophy, there have not been any studies demonstrating that they are able to block the cell death induced by severe stress. This suggests that the mechanisms underlying atrophy and death may lie on a continuum, with severe (or prolonged) stresses "recruiting" additional pathogenic pathways in addition to enhanced NMDAmediated neurotransmission. As discussed, stress increases extracellular levels of glutamate, and sustained activation of NMDA as well as non-NMDA ionotropic receptors could result in high intracellular levels of calcium. Overactivation of the glutamate ionotropic receptors is known to contribute to the neurotoxic effects of a variety of insults, including repeated seizures and ischemia (Figure 1). Neurotoxicity follows as a response to overactivation of calcium-dependent enzymes and the generation of oxygen free radicals. Stress or glucocorticoid exposure also compromises the metabolic capacity of neurons, thereby increasing the vulnerability to other types of neuronal insults.

Activation of the HPA axis appears to play a critical role in mediating these effects, because stress-induced neuronal atrophy is prevented by adrenalectomy and duplicated by exposure to high concentrations of glucocorticoids (reviewed in McEwen 1999; Sapolsky 1996, 2000). Increasing recent data also suggest a critical role for corticotropin-releasing hormone (CRH) in long-term effects of early-life stress on hippocampal integrity and function. Thus, the administration of CRH to the brains of immature rats has been demonstrated to reduce memory function throughout life; these deficits are associated with progressive loss of hippocampal CA3 neurons and chronic up-regulation of hippocampal CRH expression, effects that do not require the presence of stress levels of glucocorticoids (Brunson et al 2001). The $\mathrm{CRH}_{1}$ receptor, which binds $\mathrm{CRH}$ with higher affinity than does $\mathrm{CRH}_{2}$ receptor, plays a major role in regulating adrenocorticotrophin hormone (ACTH) release and has been implicated in animal models of anxiety. Indeed, the central administration of $\mathrm{CRH}_{1}$ antisense oligodeoxynucleotides has been demonstrated to have anxiolytic effects against both $\mathrm{CRH}$ and psychological stressors. Although $\mathrm{CRH}_{2}$ receptors appear to act in an antagonistic manner (i.e., $\mathrm{CRH}_{1}$ activates and $\mathrm{CRH}_{2}$ attenuates the stress response), its precise role is still being characterized (reviewed in Reul and Holsboer 2002). Interestingly, pretreatment with a $\mathrm{CRH}$ antagonist also attenuates the stress-induced increases in MR levels in hippocampus, neocortex, frontal cortex, and amygdala (Gesing et al 2001). Rats that underwent a stressor also showed increased ACTH and cortisol levels after the administration of an MR antagonist, suggesting that the up-regulation of MR in the stressed group is associated with increased inhibitory tone of the HPA axis. 
Together, the abundant data for the critical roles of CRH and glucocorticoids are noteworthy with respect to the pathophysiology of mood disorders, because a significant percentage of patients with mood disorders display some form of HPA axis activation, and the subtypes of depression most frequently associated with HPA activation are those most likely to be associated with hippocampal volume reductions (Sapolsky 2000). A significant percentage of patients with Cushing's disease, in which pituitary gland adenomas result in cortisol hypersecretion, are also known to manifest prominent depressive symptoms, as well as hippocampal atrophy. Additionally, some patients with Cushing's disease show a reduction in hippocampal volume that correlates inversely with plasma cortisol concentrations; after corrective surgical treatment, enlargement of hippocampal volume in proportion to the treatment-associated decrement in urinary free cortisol concentrations is observed (Simmons et al 2001; Starkman et al 1999).

The HPA axis hyperactivity in mood disorder patients is generally manifest by increased cortisol levels in plasma (especially at the circadian nadir), urine, and cerebrospinal fluid, increased cortisol response to ACTH, blunted ACTH response to $\mathrm{CRH}$ challenge, enlarged pituitary and adrenal glands, and down-regulation at postmortem of frontal cortical CRH receptors. Reduced corticosteroid receptor feedback is implicated in this process by challenge studies with dexamethasone and dexamethasone plus CRH in bipolar and unipolar subjects (McQuade and Young 2000; Reul and Holsboer 2002).

Evidence in humans suggests that decreased corticosteroid receptor number (postmortem reduction of GR messenger ribonucleic acid [mRNA]) may be present in the hippocampus of individuals with bipolar and unipolar disorder, and some antidepressants (tricyclics), electroconvulsive therapy (ECT), and mood stabilizers (lithium) may modulate GR number and/or function (reviewed in Holsboer 2000). Furthermore, transgenic mice with reduced GR have HPA and cognitive disturbance that may parallel depression in humans and that normalizes with antidepressant exposure. Finally, antisense oligonucleotides targeted to GR reduced immobility on the forced swim test, as does the antiglucocorticoid drug mifepristone (RU-486) (Korte et al 1996).

In addition to directly causing neuronal atrophy, stress and glucocorticoids also appear to reduce cellular resilience, thereby making certain neurons more vulnerable to other insults, such as ischemia, hypoglycemia, and excitatory amino acid toxicity (Sapolsky 2000). Thus, recurrent stress (and presumably recurrent mood disorders episodes, which are often associated with hypercortisolemia) may lower the threshold for cellular death/atrophy in response to a variety of physiologic (e.g., aging) and pathologic (e.g., ischemia) events. The potential functional significance of these effects is supported by the demonstration that overexpression of the glucose transporter blocks the neurotoxic effects of neuronal insults (Figure 1) (Manji and Duman 2001; Sapolsky 2000). Such processes may conceivably also play a role in the relationship between mood disorders and cerebrovascular events, considering that individuals who develop their first depressive episode in late life have an increased likelihood of showing MRI evidence of cerebrovascular disease (Chemerinski and Robinson 2000; Drevets 2000; Kumar et al 1997; Murray and Lopez 1997; Steffens and Krishnan 1998; Steffens et al 1999); furthermore, inflammatory reactions consistent with ischemia are also suggested by the findings of elevations of the intercellular adhesion molecule- 1 in dorsolateral PFC in postmortem studies of late-life depression patients (Thomas et al 2000, 2002). The precise mechanisms by which glucocorticoids exert these deleterious effects remain to be fully elucidated, but likely involve the inhibition of glucose transport (thereby diminishing capability of energy production and augmenting susceptibility to hypoglycemic conditions), and the aberrant, excessive facilitation of glutamatergic signaling (Sapolsky 2000). The reduction in the resilience of discrete brain regions, including hippocampus and potentially PFC, may also reflect the propensity for various stressors to decrease the expression of brain-derived neurotrophic factor (BDNF) in this region (Nibuya et al 1999; Smith et al 1995). The mechanisms underlying the down-regulation of BNDF by stress have not been fully elucidated. Adrenal-glucorticoids do not appear to account for these actions of stress, because administration of a high dose of glucocorticoid is not sufficient to decrease BDNF, and adrenalectomy does not block the effect of stress.

\section{Stress and Glucocorticoids Also Impair Hippocampal Neurogenesis}

The demonstration that neurogenesis occurs in the adult human brain has re-invigorated research into the cellular mechanisms by which the birth of new neurons is regulated in the mammalian brain (Eriksson et al 1998). The localization of pluripotent progenitor cells and neurogenesis occurs in restricted brain regions. The greatest density of new cell birth is observed in the subventricular zone and the subgranular layer of the hippocampus. Cells born in the subventricular zone migrate largely to the olfactory bulb and those in the subgranular zone into the granule cell layer. The newly generated neurons send out axons and appear to make connections with surrounding neurons, indicating that they are capable of integrating into the appropriate neuronal circuitry in hippocampus and cere- 
bral cortex. Neurogenesis in the hippocampus is increased by enriched environment, exercise, and hippocampaldependent learning (Gould et al 2000; Kempermann et al 1997; van Praag et al 1999). Up-regulation of neurogenesis in response to these behavioral stimuli and the localization of this process to hippocampus has led to the proposal that new cell birth is involved in learning and memory (Gould et al 2000).

Recent studies have shown that decreased neurogenesis occurs in response to both acute and chronic stress (see Gould et al 2000). Removal of adrenal steroids (i.e., adrenalectomy) increases neurogenesis, and treatment with high levels of glucocorticoids reproduces the downregulation of neurogenesis that occurs in response to stress. Aging also influences the rate of neurogenesis. Although neurogenesis continues into late life, the rate is significantly reduced (Cameron and McKay 1999). The decreased rate of cell birth could result from up-regulation of the HPA axis and higher level of adrenal-steroids that occurs in later life. Lowering glucocorticoid levels in aged animals restores neurogenesis to levels observed in younger animals, indicating that the population of progenitor cells remains stable but is inhibited by glucocorticoids (Cameron and McKay 1999). Interestingly, studies in GR knockout mice showed significant alterations in hippocampal neurogenesis (Gass et al 2000). A reduction of granule cell neurogenesis (up to $65 \%$ of control levels) was found in $\mathrm{MR}-/-$ mice, whereas $\mathrm{GR}-/-$ mice did not show neurogenic disruption, suggesting the involvement of the MR receptor in the pathogenesis of hippocampal changes observed in chronic stress and affective disorders (Gass et al 2000). These observations raise the interesting possibility that $\mathrm{CRH}$ and GR antagonists, currently being developed for the treatment of mood and anxiety disorders, may have particular utility in the treatment of elderly depressed patients. Also of potential relevance for our understanding of the neurobiology and treatment of mood disorders, ovariectomy decreases the proliferation of new cells in the hippocampus, effects which are reversed by estrogen replacement. The rate of neurogenesis fluctuates over the course of the estrus cycle in rodents, and the total rate of cell birth is higher in female rodents relative to males. In addition to potentially playing a role in the beneficial cognitive effects of estrogen, the regulation of neurogenesis by this gonadal steroid may also provide important clues about certain sexually dimorphic characteristics of mood disorders.

\section{Neurotrophic Signaling Cascades: A Focus on BDNF}

Neurotrophins are a family of regulatory factors that mediate the differentiation and survival of neurons, as well
Table 2. Acute Synaptic Effects of BDNF

- BDNF dramatically increases the frequency of spontaneously initiated action potentials in hippocampal neurons

- BDNF potentiates both excitatory and inhibitory transmission via different mechanisms

- trkB is contained in some GABAergic interneurons, neuromodulatory (e.g., cholinergic, dopaminergic, and noradrenergic) afferents, and glutamatergic afferents

- These acute synaptic effects of BDNF occur independently of its long term effects on synapse number or neuronal survival

BDNF, brain-derived neurotrophic factor; GABA, $\gamma$-aminobutyric acid.

as the modulation of synaptic transmission and synaptic plasticity (Patapoutian and Reichardt 2001; Poo 2001). The neurotrophin family now includes, among others, nerve growth factor, BDNF, neurotrophin (NT)3, NT4/5, and NT6 (Patapoutian and Reichardt 2001). These various proteins are closely related in terms of sequence homology and receptor specificity. They bind to and activate specific receptor tyrosine kinases belonging to the Trk family of receptors, including TrkA, TrkB, TrkC, and a pan-neurotrophin receptor P75 (Patapoutian and Reichardt 2001; Poo 2001). Additionally, there are two isoforms of TrkB receptors: the full-length TrkB and the truncated form of TrkB, which does not contain the intracellular tyrosine kinase domain (Fryer et al 1996). The truncated form of TrkB can thus function as a dominant-negative inhibitor for the TrkB receptor tyrosine kinase, thereby providing another mechanism to regulate BDNF signaling in the CNS (Gonzalez et al 1999). Neurotrophins can be secreted constitutively or transiently, and often in an activitydependent manner. Recent observations support a model wherein neurotrophins are secreted from the dendrite and act retrogradely at presynaptic terminals, where they act to induce long-lasting modifications (Poo 2001). Within the neurotrophin family, BDNF is a potent physiologic survival factor that has also been implicated in a variety of pathophysiologic conditions. The cellular actions of BDNF are mediated through two types of receptors: a high-affinity tyrosine receptor kinase (TrkB) and a lowaffinity pan-neurotrophin receptor (p75). TrkB is preferentially activated by BDNF and NT4/5 and appears to mediate most of the cellular responses to these neurotrophins.

Brain-derived neurotrophic factor and other neurotrophic factors are necessary for the survival and function of neurons (Mamounas et al 1995), implying that a sustained reduction of these factors could affect neuronal viability; however, what is sometimes less well appreciated is the fact that BDNF also has a number of much more acute effects on synaptic plasticity and neurotransmitter release, and it facilitates the release of glutamate, $\gamma$-aminobutyric acid (GABA), dopamine, and serotonin (Goggi et al 2002; Matsumoto et al 2001; Schinder et al 2000) (Table 2). In 


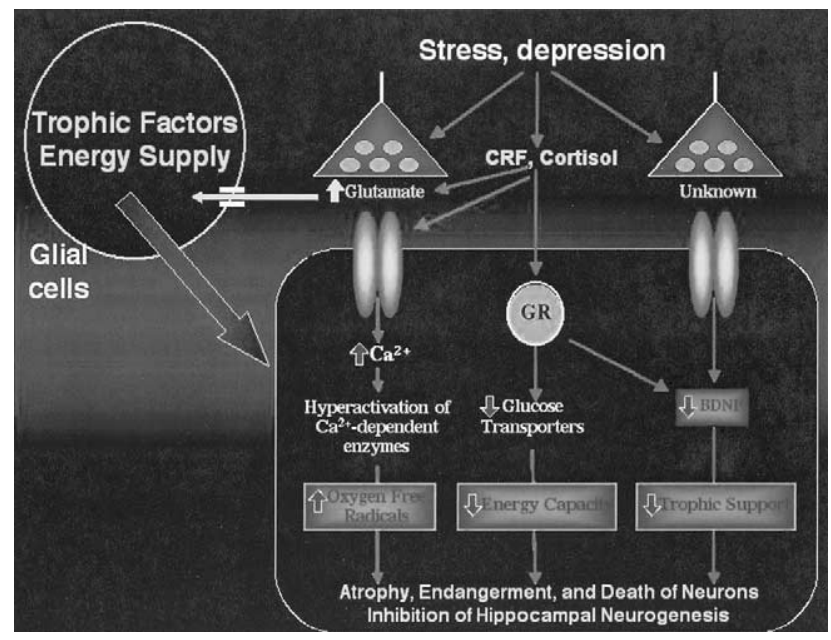

Figure 2. Cellular mechanisms by which stress and mood disorders may bring about impairments of structural plasticity. This figure depicts the multiple mechanisms by which stress and potentially affective episodes may attenuate cellular resiliency, thereby resulting in atrophy, death, and endangerment of hippocampal neurons. The primary mechanisms appear to be: 1) excessive NMDA and non-NMDA glutamatergic throughput; 2) down-regulation of cell surface glucose transporters, which are involved in bringing glucose into the cell. Reduced levels of glucose transporters thus reduce the neuron's energetic reservoir, making them susceptible to energy failure when faced with excessive demands; 3 ) reduction in the levels of BDNF, which is essential for the neuron's normal trophic support and synaptic plasticity. The well-documented reduction in glial cells may contribute to impairments of neuronal structural plasticity by reducing the neuron's energy supply and reduced glial-mediated clearing of excessive synaptic glutamate. NMDA, $N$-methyl-Daspartate glutamate receptor; CRF, corticotropin release factor; GR, glucocorticoid receptor; BDNF, brain derived neurotrophic factor. Modified and reproduced, with permission, from Manji and Duman 2001.

this context, BDNF has been shown to potentiate both excitatory and inhibitory transmission, albeit via different mechanisms; BDNF strengthens excitation primarily by augmenting the amplitude of $\alpha$-amino-3-hydroxy-5-methylisoxazole propionate (AMPA) receptor-mediated miniature excitatory postsynaptic currents but enhances inhibition by increasing the frequency of miniature inhibitory postsynaptic currents and increasing the size of GABAergic synaptic terminals. Furthermore, full-length TrkB receptor immunoreactivity has not only been found in glutamatergic pyramidal and granule cells, but also in some interneuron axon initial segments, axon terminals forming inhibitory-type synapses onto somata and dendritic shafts, and excitatory-type terminals likely to originate extrahippocampally. Together, these results suggest that TrkB is contained in some GABAergic interneurons, neuromodulatory (e.g., cholinergic, dopaminergic, and noradrenergic) afferents, and/or glutamatergic afferents (Drake et al 1999).

As discussed above, BDNF is best known for its long-term neurotrophic and neuroprotective effects, which may be very important for its putative role in the pathophysiology and treatment of mood disorders (see below). In this context, it is noteworthy that although endogenous neurotrophic factors have traditionally been viewed as increasing cell survival by providing necessary trophic support, it is now clear that their survival-promoting effects are mediated in large part by an inhibition of cell death cascades (Riccio et al 1999). Increasing evidence suggests that neurotrophic factors inhibit cell death cascades by activating the mitogen-activated protein (MAP) kinase signaling pathway and the phosphotidylinositol-3 kinase/Akt pathway (Figure 2). One important mechanism by which the MAP kinase signaling cascades inhibits cell death is by increasing the expression of the antiapoptotic protein bcl-2 (Bonni et al 1999; Finkbeiner 2000). Bcl-2 is now recognized as a major neuroprotective protein, because bcl-2 overexpression protects neurons against diverse insults, including ischemia, 1-methyl-4-phenyl1,2,3,6-tetrahydropyridine (MPTP), $\beta$-amyloid, free radicals, excessive glutamate, and growth factor deprivation (Manji et al 2001b). Accumulating data suggest that not only is bcl-2 neuropotective, it also exerts neurotrophic effects and promotes neurite sprouting, neurite outgrowth, and axonal regeneration (Chen and Tonegawa 1998; Chen et al 1997; Chierzi et al 1999; Holm et al 2001; Oh et al 1996). Moreover, a recent study demonstrated that severe stress exacerbates stroke outcome by suppressing bcl-2 expression (DeVries et al 2001). In this study, the stressed mice expressed $\sim 70 \%$ less bcl-2 mRNA than did unstressed mice after ischemia. Furthermore, stress greatly exacerbated infarct in control mice but not in transgenic mice that constitutively express increased neuronal bcl-2. Finally, high corticosterone concentrations were significantly correlated with larger infarcts in wild-type mice but not in bcl-2-overexpressing transgenic mice. Thus, enhanced bcl-2 expression appears to be capable of offsetting the potentially deleterious consequences of stressinduced neuronal endangerment, and this suggests that pharmacologically induced upregulation of bcl-2 may have considerable utility in the treatment of a variety of disorders associated with endogenous or acquired impairments of cellular resilience (see below). Overall, it is clear that the neurotrophic factor/MAP kinase/bcl-2 signaling cascade plays a critical role in cell survival in the CNS and that there is a fine balance maintained between the levels and activities of cell-survival and cell-death factors; modest changes in this signaling cascade or in the levels of the bcl-2 family of proteins (potentially due to genetic-, illness-, or insult-related factors) may therefore profoundly 
affect cellular viability. We now turn to a discussion of the growing body of data suggesting that neurotrophic signaling molecules play important roles in the treatment of mood disorders (Young 2001, 2002).

\section{Influence of Antidepressant Treatment on Cell Survival Pathways}

Seminal studies from the Duman laboratory have investigated the possibility that the factors involved in neuronal atrophy and survival could be the target of antidepressant treatments (D'Sa and Duman 2002; Duman et al 1999) (Figure 3A). These studies demonstrate that one pathway involved in cell survival and plasticity, the cyclic adenosine monophosphate (cAMP)-cAMP response elementbinding protein (CREB) cascade is up-regulated by antidepressant treatment (Duman et al 1999). A recent study has also demonstrated that antidepressant treatment in vivo increases CREB phosphorylation and CRE-mediated gene expression in mouse limbic brain regions (Thome et al 2000). Up-regulation of CREB and BDNF occurs in response to several different classes of antidepressant treatments, including norepinephrine, SSRIs, and electroconvulsive seizures, indicating that the cAMP-CREB cascade and BDNF are common postreceptor targets of these therapeutic agents (Nibuya et al 1995, 1996). In addition, up-regulation of CREB and BDNF is dependent on chronic treatment, consistent with the therapeutic action of antidepressants. A role for the cAMP-CREB cascade and BDNF in the actions of antidepressant treatment is also supported by studies demonstrating that up-regulation of these pathways increases performance in behavioral models of depression (Duman et al 1999). It has also been observed that induced CREB overexpression in the dentate gyrus results in an antidepressant-like effect in the learned helplessness paradigm and the forced swim test in rats (Chen et al 2001b). Indirect human evidence comes from studies showing increased hippocampal BDNF expression in postmortem brain of subjects treated with antidepressants at the time of death versus antidepressant-untreated subjects (Chen et al 2001).

\section{Cellular/Neurotrophic Actions of Antidepressant Treatments}

There are several reports that support the hypothesis that antidepressant treatment produces neurotrophiclike effects. One early study reported that antidepressant treatment induces a greater regeneration of catecholamine axon terminals in the cerebral cortex (Nakamura 1990). Additional studies have also examined the influence of antidepressant treatment on the atrophy of hippocampal neurons in response to stress.
Chronic administration of an atypical antidepressant, tianeptine, was reported to block the stress-induced atrophy of CA3 pyramidal neurons (Watanabe et al 1992). This was measured as a blockade of the decrease in the number and length of apical dendrite branch points. Czeh et al (2001) have recently reported on some very interesting preclinical studies, in which stress-induced changes in brain structure and neurochemistry were counteracted by treatment with tianeptine. In their study, male tree shrews subjected to a chronic psychosocial stress paradigm were found to have decreased $N$-acetylaspartate (NAA), a putative marker of neuronal viability (Moore and Galloway 2002; Tsai and Coyle 1995) measured in vivo by ${ }^{1} \mathrm{H}$ magnetic resonance spectroscopy, decreased granule cell proliferation in the dentate gyrus of the hippocampus, and a reduction in hippocampal volume as compared with nonstressed animals. These stress-induced effects were prevented/reversed in shrews treated concomitantly with tianeptine (Czeh et al 2001); once again, however, the generalizability of these effects to other classes of antidepressants is unclear. Additional studies are needed to further characterize the influence of these and other classes of typical and atypical antidepressants on the atrophy of CA3 neurons. Moreover, the neurotrophic/ neuroprotective effects of antidepressants in other models of cell damage or atrophy must also be examined.

\section{Antidepressants Also Regulate Hippocampal Neurogenesis: Is This Actually Relevant in the Treatment of Depression?}

Recent studies have shown that chronic, but not acute, antidepressant treatment also increases the neurogenesis of dentate gyrus granule cells (D'Sa and Duman 2002; Jacobs et al 2000; Manev et al 2001). These studies demonstrate that chronic administration of different classes of antidepressant treatment, including norepinephrine, SSRIs, and electroconvulsive seizures, increases the proliferation and survival of new neurons. By contrast, increased neurogenesis is not observed in response to chronic administration of nonantidepressant psychotropic drugs. Studies demonstrating that neurogenesis is increased by conditions that stimulate neuronal activity (e.g., enriched environment, learning, exercise) suggest that this process is also positively regulated by, and may even be dependent on, neuronal plasticity (Kempermann 2002). The enhancement of hippocampal neurogenesis by antidepressants serves to highlight the degree to which these effective treatments are capable of regulating long-term neuroplastic events in the brain; however, at this point, it is not completely clear precisely what the clinical significance of enhancement of adult hippocampal neurogenesis by antidepressants truly represents. In view of the 
A

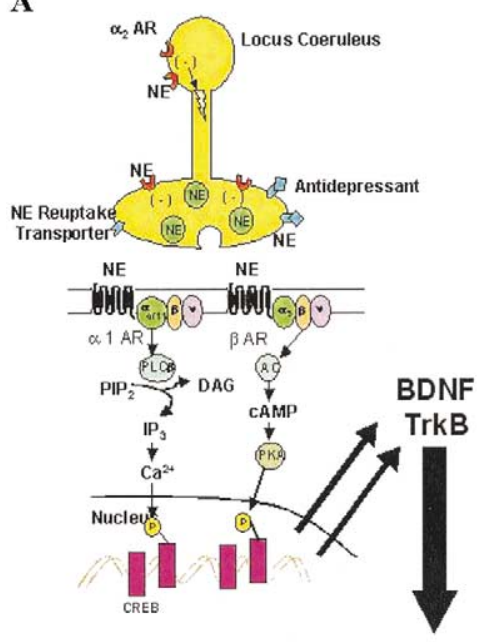

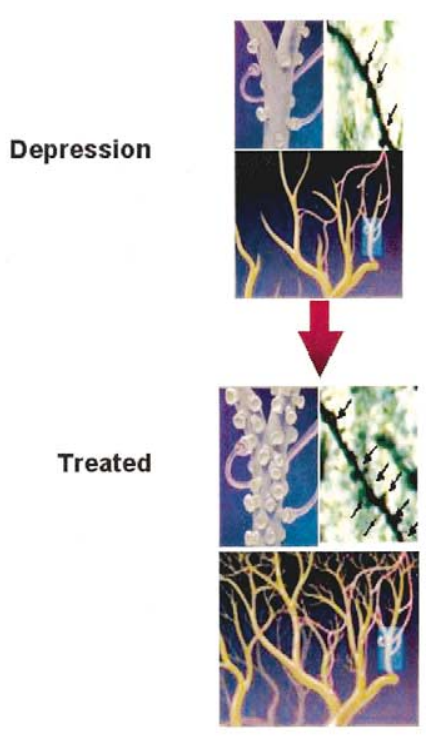

B

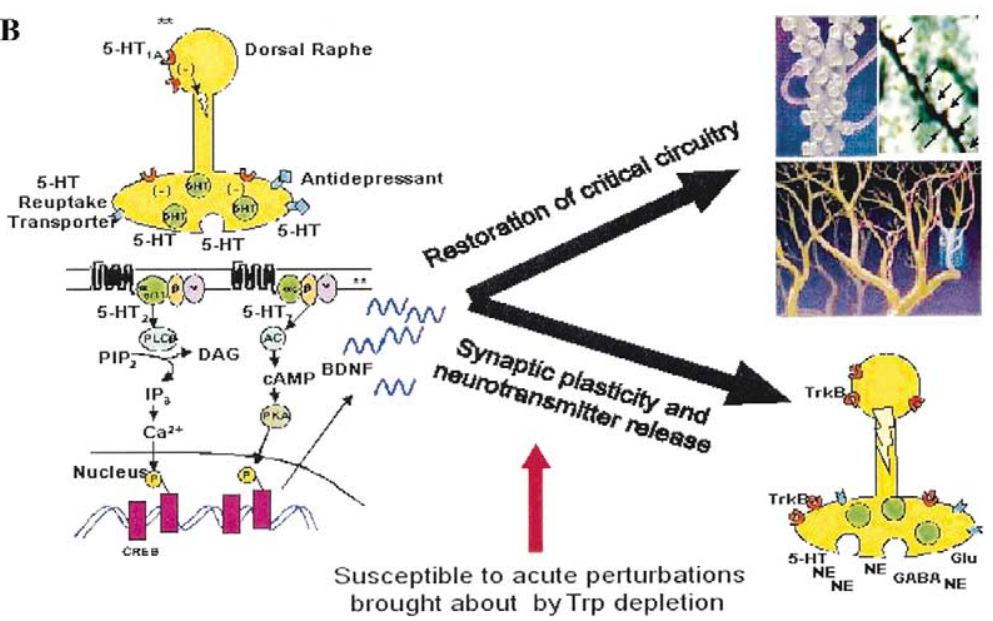

Figure 3. (A) Neurotrophic effects of antidepressants. Antidepressant treatment increases synaptic levels of norepinephrine (NE) and serotonin (5-HT) via blocking the reuptake or breakdown of these monoamines. This results in activation of intracellular signal transduction cascades, one of which is the cAMP-CREB cascade. Chronic antidepressant treatment increases Gs coupling to adenylyl cyclase (AC), particulate levels of cAMP-dependent protein kinase (PKA), and CREB. CREB can also be phosphorylated by $\mathrm{Ca}^{2+}$-dependent protein $\mathrm{ki}$ nases, which can be activated by the phosphatidylinositol pathway or by glutamate ionotropic receptors (e.g., NMDA) (not shown). One gene target of antidepressant treatment and the cAMP-CREB cascade is BDNF, which contributes to the cellular processes underlying neuronal plasticity, and restoration/enhancement of neural connectivity mechanisms, which are essential for healthy affective functioning. The restoration of the circuitry allows adequate "throughput" of critical neurotransmitters to treat depression. (B) Resolution of the tryptophan depletion conundrum of the neurotrophic hypothesis of antidepressant drug action. Treatment of depression is attained by providing both trophic and neurochemical support; the trophic support restores normal synaptic connectivity, thereby allowing the chemical signal to reinstate the optimal functioning of critical circuits necessary for normal affective functioning. Brain-derived neurotrophic factor also facilitates the release of neurotransmitters that act on this restored, intact circuit. Acute reduction in synaptic serotonin levels via its effects on reducing BDNF levels is capable of rapidly reducing the release of a number of neurotransmitters. Thus, tryptophan depletion diets are capable of inducing a depressive relapse in selective serotonin reuptake inhibitor-treated patients via the effects on neurotransmitter release, although likely not having major effects on structural brain changes. cAMP, cyclic adenosine monophosphate; CREB, cAMP response element-binding protein; NMDA, $N$-methyl-D-aspartate; BDNF, brain-derived neurotrophic factor; AR, adrenoreceptors; PLC, phospholipase C; PIP2, phosphoinositide 4,5-biphosphate; DAG, diacylglycerol; IP, inositolmonophosphate; $\mathrm{p}$, phosphorylated; TrkB, specific tyrosine kinases receptor; Trp, tryptophan; GABA, $\gamma$-aminobutyric acid; Glu, glutamate. Modified and reproduced, with permission, from Nestler et al 2002 and Payne et al 2002. opposite effects of stress and antidepressants on hippocampal neurogenesis, it is quite plausible that alterations in hippocampal neurogenesis are fundamental to the clinical syndrome of depression (D'Sa and Duman 2002; Jacobs et al 2000; Kempermann 2002); however, as Kempermann (2002) has clearly articulated, much more 
research is required to adequately link changes in adult hippocampal neurogenesis to the pathophysiology and treatment of depression.

A role in the memory impairment that occurs in depression represents the most intuitively obvious potential clinical correlate for hippocampal neurogenesis; however, although mouse strains with lower neurogenesis tend to be known as strains with reduced performance on learning tasks, old mice, who have very little adult neurogenesis (less than one tenth that of young adults) are not impaired on learning tasks to the same degree (see Kempermann 2002 for an excellent discussion). Although there is yet no direct link between adult hippocampal neurogenesis and mood and emotion, the key role of the hippocampus in regulating diverse physiologic and neurovegetative functions suggests that impairments of neurogenesis may also contribute to other facets of the clinical syndrome of depression (D'Sa and Duman 2002; Jacobs et al 2000; Kempermann 2002). A critical step will be the demonstration that inhibition of antidepressant-induced adult hippocampal neurogenesis results in an attenuation of the behavioral effects of antidepressants. Given the inherent difficulty in selectively inhibiting adult hippocampal neurogenesis (i.e., without producing a large number of other neuroplastic effects that may also have behavioral consequences), it is likely going to be more straightforward to investigate correlations between antidepressant-induced neurogenesis and behavioral effects in different mouse strains. In this context, it is noteworthy that Kempermann and associates have demonstrated marked genetic influences on hippocampal neurogenesis in adult mice (discussed in Kempermann 2002). Furthermore, genetic factors have also been clearly demonstrated to play a critical role in determining performance and sensitivity to different types of antidepressant drugs in rodent models of depression (notably forced swim and tail suspension). Ongoing studies (Kempermann 2002, personal communication) attempting to correlate antidepressant-induced changes in hippocampal neurogenesis in different mouse strains with performance in depression models should provide much needed information about the role of hippocampal neurogenesis in antidepressant drug action.

\section{If Neurotrophic Effects Are Actually Involved in the Mechanisms of Action of Antidepressants, Why Does Tryptophan Depletion Cause Rapid Relapse in SSRI-Treated Patients?}

A problem to be addressed with the neurotrophic hypothesis of antidepressant drug action is the "tryptophan depletion conundrum." Thus, it is now well established that patients successfully treated with SSRIs show a rapid depressive relapse following experimental procedures that deplete tryptophan and serotonin (Aberg-Wistedt et al 1998; Delgado et al 1991, 1999). How are such rapid effects to be reconciled with the postulated neurotrophic actions of antidepressants? It is our contention that treatment of depression is attained by providing both trophic and neurochemical support; the trophic support restores normal synaptic connectivity, thereby allowing the chemical signal to reinstate the optimal functioning of critical circuits necessary for normal affective functioning. As discussed already, BDNF also facilitates the release of neurotransmitters that act on this restored, intact circuit. Acute reduction in synaptic serotonin levels via its effects on reducing BDNF levels is capable of rapidly reducing the release of a number of neurotransmitters. Thus, tryptophan depletion diets are capable of inducing a depressive relapse in SSRI-treated patients via the effects on neurotransmitter release, although likely not having acute major effects on brain structure per se (Figure 3B).

\section{Do Effective Antidepressant Potentiating Strategies Also Affect Neurotrophic Signaling Cascades?}

In seeking to identify novel strategies for the development of improved therapeutics for difficult-to-treat depression, an investigation of the mechanisms by which effective antidepressant potentiating agents exert their beneficial effects may provide invaluable clues. In this context, the two treatment modalities that have most clearly been demonstrated to exert antidepressant potentiating effects, at least in certain patients, are lithium and thyroid hormones. Although both modalities unquestionably exert a multitude of effects of various neurochemical systems, it is noteworthy that a growing body of data are showing that they exert major neurotrophic effects in a variety of paradigms (see below).

\section{Lithium Robustly Activates Neurotrophic Signaling Cascades}

Lithium has been used to augment the efficacy of antidepressant medications for more than 15 years. It has been unequivocally established in controlled studies that approximately half of all treatment-refractory depressed patients respond to an addition of lithium to their ongoing antidepressant regimen (de Montigny et al 1983; Heninger et al 1983). Although lithium potentiation is more efficacious in bipolar patients, it also has clear efficacy in the treatment of unipolar depressive patients. The lithium augmentation strategy derived from de Montigny's heuristic proposal that the enhancement of ascending presynaptic serotonergic function would translate into potentia- 
tion of antidepressant efficacy (de Montigny et al 1983); however, considerable data have shown that lithium can affect neurotrophic signaling cascades, and it is our contention that these effects may also underlie its efficacy in potentiating the efficacy of diverse classes of antidepressants.

As discussed above, several endogenous growth factors, including nerve growth factor and BDNF, exert many of their neurotrophic effects via the MAP kinase-signaling cascade. In view of the important role of MAP kinases in mediating long-term neuroplastic events, it is noteworthy that lithium, at therapeutically relevant concentrations, has recently been demonstrated to robustly activate the extracellular signal-regulated kinase MAP kinase cascade in human neuroblastoma SH-SY5Y cells and in critical limbic and limbic-related areas of rodent brain (Yuan et al 2001) (Figure 2). Interestingly, neurotrophic factors are now known to promote cell survival by activating MAP kinases to suppress intrinsic, cellular apoptotic machinery, not by inducing cell survival pathways (see above) (Adams and Cory 1998; Bonni et al 1999; Chen et al 1997; Finkbeiner 2000; Pettmann and Henderson 1998; Riccio et al 1999; Thoenen 1995). Thus, a downstream target of the MAP kinase cascade, ribosomal S-6 kinase (Rsk) phosphorylates CREB, and this leads to induction of bcl-2 gene expression (Figure 2). Consistent with an activation of neurotrophic signaling cascades, chronic treatment of rats with "therapeutic" doses of lithium produces a doubling of bcl-2 levels in frontal cortex, effects which were primarily due to a marked increase in the number of bcl-2 immunoreactive cells in layers II and III of frontal cortex (Chen G et al 1999, 2001; Du et al, in press). Interestingly, the importance of neurons in layers II-IV of the frontal cortex in mood disorders has recently been emphasized, because primate studies indicate that these areas are important for providing connections with other cortical regions and that they are targets for subcortical input (Rajkowska 2000a).

In addition to its robust effects on bcl-2, lithium's effects on other signaling pathways and transcription factors may also contribute to its neuroprotective effects. Perhaps foremost among these is glycogen synthase kinase (GSK)-3 $\beta$ (Gould and Manji 2002; Li et al 2002). Klein and Melton (1996) were the first to make the seminal observation that lithium, at therapeutically relevant concentrations, is an inhibitor of GSK-3 $\beta$. Glycogen synthase kinase $3 \beta$ not only controls developmental patterns in diverse organisms (including mammals) but also plays an important role in the mature CNS, by regulating various cytoskeletal processes, as well as long-term nuclear events via phosphorylation of $\mathrm{c}$-jun, nuclear translocation of $\beta$-catenin, and nuclear export of NF-ATc, a specific transcription factor (reviewed in Gould and Manji 2002; Li et al 2002; Phiel and Klein 2001). Glycogen synthase
Table 3. Neurotrophic and Neuroprotective Effects of Lithium

Protects Cultured Cells of Rodent and Humanneuronal Origin in Vitro $^{+}$from:

- Glutamate

- High concentrations of calcium

- $\mathrm{MPP}^{+}$

- $\beta$-amyloid

- Aging-induced cell death

- HIV regulatory protein, Tat

- HIV gp120 envelope protein

- Glucose deprivation

- Growth factor or serum deprivation

- Toxic levels of anticonvulsants

- Platelet activating factor (PAF)

- Aluminum toxicity

- Low potassium concentrations

- C2-ceramide

- Ouabain

- GSK-3 $\beta$ \& staurosporine/heat shock

- $\beta$-bungarotoxin

Enhances Regeneration of Retinal Ganglion Cells

Enhances Hippocampal Neurogenesis in Adult Mice

Protects Rodent Brain in Vivo from:

- Cholingergic lesions

- Radiation injury

- Middle cerebral artery occlusion (model of stroke)

- HIV gp120 envelope protein injection (model of HIV-associated dementia)

- Quinolinic Acid infusion (model of Huntington's disease)

- Aluminum maltolate

Human Effects

- No subgenual PFC gray matter volume reductions in crosssectional MRI studies

- No reductions in amygdala glial density in postmortem cell counting studies

- Increased total gray matter volumes on MRI compared to untreated BD patients in cross-sectional studies

- Increases in NAA (marker of neuronal viability) levels in BD patients in longitudinal studies

- Increased gray matter volumes in BD patients in longitudinal studies

$\mathrm{MPP}^{+}$, 1-methyl-4-phenylpyridinium ion; HIV, human immunodeficiency virus; GSK, glucogen synthase kinase; PFC, prefrontal cortex; MRI, magnetic resonance imaging; $\mathrm{BD}$, bipolar disorder; NAA, $N$-acetylaspartate.

kinase $3 \beta$ has also been involved in regulating the phosphorylation of tau and $\beta$-catenin, both of which have been implicated in certain types of disease-related neuronal death. In this context, several studies have found that inhibition of GSK-3 $\beta$ by lithium reduces tau phosphorylation, effects which likely occur to some degree at therapeutically relevant lithium concentrations (see Jope 1999 for an excellent discussion). Most recently, it has been demonstrated that the chronic (3-week) administration of lithium also increases $\beta$-catenin levels in rodent brain (Gould et al, unpublished data), compatible with inhibition of GSK-3 $\beta$ during chronic in vivo administration of the agents under therapeutic paradigms.

In addition to its robust effects on neurotrophic signaling proteins, chronic lithium administration has also been 
demonstrated to enhance cellular resiliency by attenuating aberrant NMDA-mediated glutamatergic functioning. Thus Nonaka et al (1998) found that chronic treatment of cultured rat cerebellar, cortical, and hippocampal neurons with therapeutically relevant concentrations of lithium protected against glutamate-induced excitotoxicity, in particular NMDA-mediated apoptosis. Subsequent studies by the same investigators showed that although lithium did not alter the total protein levels of NR1, NR2A, and NR2B subunits of NMDA receptors, lithium protection against glutamate excitotoxicity in rat cerebral neurons may be a result of reducing the level of NR2B phosphorylation at Tyr1472 (Hashimoto et al 2002). NR2B phosphorylation has been reported to be positively correlated with NMDA receptor-mediated synaptic activity and excitotoxicity. It is also possible that lithium modulates glutamatergic neurotransmission by affecting the non-NMDA receptorsensitive channels (Karkanias and Papke 1999), and chronic lithium treatment (plasma levels $\sim .7 \mathrm{mmol} / \mathrm{L}$ ) has been shown to up-regulate synaptosomal uptake of glutamate in mice (Hokin et al 2000).

Consistent with the cytoprotective effects that would be expected by attenuation of NMDA-mediated excitotoxicity and, more importantly, bcl-2 up-regulation, lithium, at therapeutically relevant concentrations, has been shown to exert neuroprotective effects in a variety of preclinical paradigms (Table 3). Thus, lithium has been demonstrated to protect against the deleterious effects of glutamate, NMDA receptor activation, aging, serum/nerve growth factor deprivation, ouabain, thapsigargin (which mobilizes intracellular 1-methyl-4-phenylpyridinium ion $\left[\mathrm{MPP}^{+}\right]$), $\mathrm{Ca}^{2+}$ and $\beta$-amyloid in vitro ( $\mathrm{Du}$ et al, in press). In addition to the demonstration of protective effects in vitro, a number of studies have also investigated lithium's neuroprotective effects in vivo (summarized in Table 4). Most notably, chronic lithium has also been shown to exert dramatic protective effects against middle cerebral artery occlusion, reducing not only the infarct size (56\%) but also the neurologic deficits (abnormal posture and hemiplegia) (Nonaka and Chuang 1998). More recently, the same research group has demonstrated that chronic in vivo lithium treatment robustly protects neurons in the striatum from quinolinic acid-induced toxicity, in a putative model of Huntington's disease (Wei et al 2001).

\section{Lithium Exerts Not Only Protective but Also Regenerative Effects at Therapeutically Relevant Concentrations}

Studies have recently been undertaken to determine whether lithium supports the survival and axon regeneration of retinal ganglion cells (RGCs), a model that has been used to study glaucoma, optic nerve neuritis, and the degeneration of RGCs (Chen et al 1997; reviewed in Huang et al 2003). In general, following injury, the postnatal mammalian optic nerve, like many other axonal pathways in the CNS, regenerates poorly; most often, injured RGCs undergo apoptotic cell death (Chen et al 1997; reviewed in Huang et al 2003). Although this regenerative failure has long been attributed to extrinsic inhibitors in the environment of the mature brain, seminal research by the Chen and Tonegawa laboratory (Chen et al 1997) has demonstrated that mature RGCs lack an intrinsic component to initiate axonal growth after injury and that this intrinsic component is the neurotrophic protein bcl-2. Investigators have therefore postulated that a prerequisite for successful regeneration of severed optic nerves in adult mammals is the activation of an intrinsic regenerative mechanism of RGC axons, namely the induction of bcl-2 expression in neurons. Studies were therefore undertaken to determine whether lithium would not only prevent injury-induced degeneration of RGCs and other CNS neurons but also promote the regeneration of their axons (Huang et al 2003). These studies showed that lithium, acting directly on RGCs, supports both neuronal survival and axon regeneration at its established therapeutic concentrations (.5-1.2 mmol/L) (Huang et al 2003).

\section{Lithium Also Increases Hippocampal Neurogenesis}

To investigate the effects of chronic lithium on hippocampal neurogenesis, mice were treated with "therapeutic" lithium (plasma levels $.97 \pm .20 \mathrm{mmol} / \mathrm{L}$ ), for $\sim 4$ weeks. After treatment with lithium for 14 days, the mice were administered single doses of BrdU (bromodeoxyuridine, a thymidine analog that is incorporated into the deoxyribonucleic acid of dividing cells) for 12 consecutive days. Lithium treatment continued throughout the duration of the BrdU administration. It was found that chronic lithium administration does, indeed, result in an increase in the number of BrdU-positive cells in the dentate gyrus (Chen et al 2000). Moreover, approximately two thirds of the BrdU-positive cells also double-stained with the neuronal marker NeuN, confirming their neuronal identity. Double staining of BrdU and bcl-2 was also observed, and studies using bcl-2 transgenic animals are currently underway to delineate the role of bcl-2 overexpression in the enhanced hippocampal neurogenesis observed.

\section{Human Evidence for the Neurotrophic Effects of Lithium}

Although the body of preclinical data demonstrating neurotrophic and neuroprotective effects of mood stabilizers is striking, considerable caution must clearly be exercised in extrapolating to the clinical situation with humans. In view of lithium's robust effects on the levels of the 
cytoprotective protein bcl-2 in the frontal cortex, Drevets and associates re-analyzed older data demonstrating $\sim 40 \%$ reductions in subgenual PFC volumes in familial mood disorder subjects (Bowley et al, in press). Consistent with neurotrophic/neuroprotective effects of lithium, they found that the patients treated with chronic lithium or valproate exhibited subgenual PFC volumes that were significantly higher than the volumes in non-lithium- or valproate-treated patients, and not significantly different from control subjects. In a more recent study, Bowley and colleagues have investigated glial cell densities in mood disorder patients. Although the sample sizes are quite small, they made the intriguing observation that unipolar patients exhibited reduced glial cell densities, whereas only the bipolar patients off chronic lithium or valproate exhibited similar reductions (Bowley et al, in press).

Although the results of the aforementioned studies suggest that mood stabilizers may have provided neuroprotective effects during naturalistic use, considerable caution is warranted in view of the small sample size and cross-sectional nature of the studies. To investigate the potential neurotrophic effects of lithium in humans more definitively, a longitudinal clinical study was recently undertaken using proton magnetic resonance spectroscopy to quantitate NAA (a putative marker of neuronal viability) levels (Tsai and Coyle 1995). Four weeks of lithium treatment produced a significant increase in NAA levels, effects which were localized almost exclusively to gray matter (Moore et al 2000a). These findings provide intriguing indirect support for the contention that chronic lithium increases neuronal viability/function in the human brain. Furthermore, a $\sim .97$ correlation between lithiuminduced NAA increases and regional voxel gray matter content was observed, thereby providing evidence for co-localization with the regional-specific bcl-2 increases observed (e.g., gray vs. white matter) in the rodent brain cortices. These results suggest that chronic lithium may not only exert robust neuroprotective effects (as has been demonstrated in a variety of preclinical paradigms), but also exerts neurotrophic effects in humans.

A follow-up volumetric MRI study has demonstrated that 4 weeks of lithium treatment also significantly increased total gray matter content in the human brain (Moore et al 2000b), suggesting an increase in the volume of the neuropil (the moss-like layer composed of axonal and dendritic fibers that occupies much of the cortex gray matter volume). A finer-grained subregional analysis of this brain imaging data is ongoing and clearly shows that lithium produces a regionally selective increase in gray matter, with prominent effects being observed in hippocampus and caudate (Moore et al, unpublished data). Furthermore, no changes in overall gray matter volume are observed in healthy volunteers treated chronically with lithium, suggesting that lithium is truly producing a reversal of illness-related atrophy, rather than nonspecific gray matter increases. Ongoing studies are attempting to determine the precise relationship between the lithiuminduced increases in regional NAA levels and gray matter volumes and treatment response.

In this context, a preliminary electroconvulsive seizures study of severely depressed patients is noteworthy. Michael and colleagues (Michael et al, in press) investigated the effects of a course of electroconvulsive seizures on NAA levels in left amygdalar region in 28 severely depressed patients. They found that significant increase in NAA was observed only in electroconvulsive seizures responders $(n=14)$. Moreover, 5 of 14 nonresponders to ECT monotherapy were then treated with adjunctive antidepressants (while electroconvulsive seizures continued) and re-scanned; the investigators found that this group showed both clinical improvement and a significant increase in NAA. Although preliminary, these clinical results suggest that the neurotrophic effects of antidepressant treatments (and likely lithium) are indeed associated with treatment response (although a causal relationship has yet to be established).

\section{Do Thyroid Hormones Also Exert Neurotrophic Effects?}

The clinical efficacy of the administration of thyroxine (T4) and/or triiodothyronine (T3) as an adjunct to antidepressant treatment has been reasonably well established. Furthermore, there is ample evidence to associate thyroid dysfunction with mood disorders. Indeed, one of the most obvious symptoms of overt hypothyroidism is affective disturbance, and abnormal thyroid activity, particularly subclinical hypothyroidism, is present in a disproportionately large number of patients with affective disorder (Haggerty and Prange 1995). Additionally, there is some evidence that depressed patients with either hypothyroidism and/or an antithyroid autoimmune response may be less responsive to antidepressant treatment. This is in agreement with studies of thyroidectomized animals using the forced-swim and escape-deficit models of depression.

There is no clear-cut mechanism for the antidepressant-potentiating effects of thyroid supplementation, although most research in this area has been focused on the noradrenergic and serotonergic systems, and the interested reader is referred to several excellent reviews (Joffe 1997; Prange 1996). Here we focus on the effects of thyroid hormones on intracellular signaling (particularly the cAMP cascade) and neurotrophic effects. Effects of thyroid activity have been noted at the level of G-proteins 
regulating the cAMP signaling cascade; specifically, hypothyroid rats typically have significantly more $\mathrm{G} \alpha_{\mathrm{i}}$ (the $\mathrm{G}$ protein that inhibits adenylyl cyclase) and reduced $\mathrm{G} \alpha_{\mathrm{s}}$ (the $\mathrm{G}$ protein that stimulates adenylyl cyclase) in a variety of tissues, including brain. Moreover, euthyroid rats administered T3 have reduced levels of $\mathrm{G} \alpha_{\mathrm{i}}$ (Orford et al 1991; Orford et al 1992). The net effect of these G protein changes produced by hypothyroid states is an attenuation of cAMP signaling, effects which undoubtedly play a role in the impaired lipolysis and thermogenesis characteristic of hypothyroid states. Moreover, similar impairments of cAMP signaling in the brain may play a role in depressive symptomatology often observed in hypothyroid states. As a corollary, administration of thyroid hormones would be expected to enhance cAMP signaling and, as discussed above, potentially exert neurotrophic effects via CREB activation. Indeed, a number of studies performed by Ruiz-Marcos and colleagues have characterized a potentially important effect of thyroid status on cortical neurons. These researchers measured the density of dendritic spines of layer $\mathrm{V}$ pyramidal neurons in control and thyroidectomized rats and determined that hypothyroidism causes a significant reduction in their number (Kalaria and Prince 1986; Ruiz-Marcos et al 1979, 1980, 1994). This effect was present in both juvenile and adult rats and could be reversed, in a dose-dependant fashion, by thyroxine treatment. Similar effects have also been noted in the caudate nucleus (Lu and Brown 1977a, 1977b).

In hippocampal development, thyroid hormone has been shown to have several effects (Gould et al 1990, 1991); thus, T3 increases the number of granule cells in the dentate gyrus, the somatic and dendritic tree size of CA3 neurons, and the dendritic spine density of CA1 neurons. There is also data to suggest that thyroid hormone strengthens the cholinergic septohippocampal projection. Whether any of these effects are significantly present in adulthood remains to be established; however, it is notable that thyroid hormone increases neurogenesis in the specific region where neurogenesis is known to occur throughout life. With respect to bcl-2, thyroidectomy reduces the expression of this important antiapoptotic protein in the cerebellum, at least until postnatal day 30 . Concordantly, T3 enhances the expression of bcl-2 in cultured cerebellar granule cells. It is important to note that, despite evidence that $\mathrm{T} 3$ increases neuronal proliferation, some researchers have found overall increases in BrdU labeling in hypothyroid animals. These findings can be reconciled by the hypothesis that $\mathrm{T} 3$ promotes the differentiation of progenitor cells.

The evidence reviewed thus far clearly suggests the following:
Table 4. Summary of the Differences in the Neurotrophic Properties of Antidepressants and Lithium: Evidence from Current Studies

- Antidepressants exert major effects on CREB and BDNF expression in rat hippocampus

- Antidepressants may exert modest effects on ERK activation in rat brain

- Lithium exerts major effects on ERK activation in rat frontal cortex and hippocampus

- Lithium exerts major effects on bcl-2 in rat frontal cortex

- Cross-sectional neuroimaging studies suggest that patients treated with chronic lithium or VPA do not show subgenual prefrontal cortex atrophy; patients treated with SSRIs show similar atrophy to untreated patients

- Longitudinal studies show that chronic lithium increases the levels of NAA in areas of brain in bipolar patients; there are no similar published studies with VPA or antidepressants

- Longitudinal studies show that chronic lithium increases gray matter volumes in bipolar patients; there are currently no similar published studies with antidepressants

CREB, cyclic adenosine monophosphate response element-binding protein; BDNF, brain-derived neurotrophic factor; ERK, extracellular response kinase; VPA, valproic acid; SSRIs, selective serotonin reuptake inhibitors; NAA, $\mathrm{N}$ acetylaspartate.

1. Recurrent mood disorders are associated with impairments of neuroplasticity and cellular resilience.

2. Abnormalities of the $\mathrm{CRH} / \mathrm{glucocorticoid}$ system and the glutamatergic system may contribute to the impairments of cellular resilience observed in patients with mood disorders.

3. Chronic antidepressants regulate neurotrophic signaling cascades.

4. Effective antidepressant potentiating strategies exert also exert neurotrophic effects, but by distinct mechanisms from first degree antidepressants (see Table 4); these latter observations suggest that if enhancement of neurotrophic signaling and cellular resilience is necessary for adequate antidepressant response, potentiating agents may produce effects that are additive to those of first degree antidepressants.

We now turn to a discussion of strategies being used to investigate the putative efficacy of plasticity enhancers as novel antidepressant agents.

\section{The Glutamatergic System as a Target for Novel Antidepressant Treatments}

Evidence for an association between alterations of brain glutamatergic neurotransmission and the pathophysiology of mood disorders has been growing since the 1950s, when D-cycloserine, a partial agonist at the NMDA receptor glycine site used as a part of multidrug antituberculosis treatment, was reported to have a mood elevating effects (Heresco-Levy and Javitt 1998; see Krystal et al 2002 for 
Table 5. Preclinical and Clinical Data Supporting the Role of the Glutamatergic System in the Pathophysiology and Treatment of Mood Disorders

Study Major Finding

Relevant preclinical findings Reynolds and Miller 1988

Trullas and Skolnick 1990

Skolnick et al 1996

Nowak et al 1996

Dixon and Hokin 1998

Boyer et al 1998

Bouron and Chatton 1999

Michael-Titus et al 2000

Chen A et al 2001a

Li et al 2001

Relevant clinical findings

Drug trials

Crane 1959

Parkes et al 1970

Vale et al 1971

Calabrese et al 1999

Berman et al 2000

Glutamate receptor studies Holemans et al 1993

Nowak et al 1995a

Meador-Woodruff et al 2001

Glutamate levels: MRS

Castillo et al 2000

Auer et al 2000

Tricyclic antidepressants slowed the dissociation rate of the NMDA antagonist [3H]-MK801 in a similar manner to $\mathrm{Zn} 2+$

Competitive NMDA antagonist AP-7, noncompetitive antagonist dizolcipine, and a partial agonist at strychnine-insensitive glycine receptors ACPC, mimicked the effects of clinically effective antidepressants in inescapable stress model in rats

Chronic (14 days) antidepressant administration (17 different antidepressants, specially studied in imipramine, citalopram, and ECT) cause adaptive changes in radioligand binding to NMDA (CGP39653, DCKA, and $(3 \mathrm{H})$ dizocilpine) in mice

Chronic citalopram in mouse, lowered 6.2-fold high-affinity glycine displaceable (3H)CGP-39653 binding to glutamate receptors and reduced 1.5 -fold the potency of glycine to inhibit $(3 \mathrm{H})$ DCKA binding in cortex. Also increases aspartate concentration $110 \%$ in cortex and 33\% in hippocampus

Chronic lithium up-regulates and stabilizes glutamate uptake by presynaptic nerve endings in mouse cerebral cortex

Chronic (16 days) of citalopram in mouse, lowered NMDA $\varepsilon 1$-subunit mRNA level invfrontal cortex, CA2 of hippocampus, and amygdala, whereas imipramine does it only in amydgala. Imipramine lowered NMDA $\varepsilon 2$-subunit mRNA level in cortex, CA1-4 of hippocampus, and amygdala, whereas citalopram does it only in amygdala. Both drugs reduced transcript levels of $\xi$-subunit in cortex, thalamus, striatum and cerebellum

Desipramine enhanced spontaneous vesicular release of glutamate in hippocampal neurons dissociated from neonatal rats

Imipramine and phenelzine decreased potasium stimulated glutamate outflow in rat prefrontal cortex and not in striatum

Ketamine pretreatment attenuate ECS-induced mossy fiber sprouting in dentate gyrus and BDNF expression in medial prefrontal cortex and the dentate gyrus, in rats

AMPA receptor potentiator LY392098 (a biarylpropylsulfonamide) produce antidepressant-like effect in rats and mice

D-Cycloserine in tuberculosis

Antiparkinsonian response to amantadine (double-blind cross-over study)

Antidepressant response to amantadine (randomized placebo-controlled study)

Antidepressant response to lamotrigine (double-blind placebo-controlled study)

Antidepressant response to ketamine (double-blind placebo-controlled study)

Binding of (H3) dizocilpine sites

High-affinity glycine displaceable (3H)CGP-39653 binding to Glu receptors

NMDA mRNA subunits levels in striatum

Glx/Gln ratio levels in frontal and temporal cortex, and basal ganglia Glx levels
Antidepressant response in tuberculosis depressed patients Significant improvement in mood and relief of parkinsoniau symptoms in 37 patients

Significant antidepressant efficacy in 40 depressed patients

Significant antidepressant efficacy in 195 depressed BPDI patients

Improve depressive symptoms in depressed patients ( 8 MDD, 1BPD) lasting longer (3 days) than euphoric effects (hours)

No changes of binding in 22 depressed, medication-free suicide victims, in cortex, hippocampus, thalamus, and basal ganglia. Negative correlation between age and NMDA receptor binding in frontal cortex suicide victims

Reduced in suicide victims ( $50 \%$ of them depressed) vs. controls, in frontal cortex

Postmortem analysis. Only NR2D (a subunit of NMDA receptor) mRNA is higher in BPD (15) vs. MDD (15). Only gluR1 (a subunit of AMPA receptor) mRNA is lower in BPD vs. controls (15). (3H)AMPA binding was higher in BPD vs. MDD.

Elevated in frontal lobe and basal ganglia in BPD medication free children vs. controls

Decreased in anterior cingulate cortex of depressed patients vs. controls ( 7 patients were medication free and 12 under antidepressant treatment; $1 \mathrm{BPD}$ and $18 \mathrm{MDD}$ ) 
Table 5. Continued

\begin{tabular}{|c|c|c|}
\hline Study & Major Finding & \\
\hline \multicolumn{3}{|c|}{ Glutamate, Glutamine and Glycine: CSF, Plasma and Platelet levels } \\
\hline Levine et al 2000 & CSF Gln levels & $\begin{array}{l}\text { Elevated in medication free depressed patients vs. control } \\
\text { (2 BPD, 16MDD) and correlated with CSF magnesium } \\
\text { level }\end{array}$ \\
\hline Mathis et al 1988 & Gln plasma level & $\begin{array}{l}\text { Gln level higher in } 59 \text { depressive patients (MDD, BPD) vs. } \\
\text { controls }\end{array}$ \\
\hline Altamura et al 1993 & Glu plasma and platelet level & $\begin{array}{l}\text { Increased plasmatic and decreased platelet level in } \\
\text { medication-free depressed patients (4 MDD, } 11 \text { BPD) vs. } \\
\text { controls }\end{array}$ \\
\hline Altamura et al 1995 & Glu and Gly plasma levels & Lower in 25 MDD medication-free patients vs. controls \\
\hline Mauri et al 1998 & Glu plasma levels & $\begin{array}{l}\text { Higher Glu plasma level in } 29 \text { MDD patients vs. controls, } \\
\text { not altered by fluvoxamine }\end{array}$ \\
\hline Maes et al 1998 & Glu, Gln plasma levels & $\begin{array}{l}\text { No differences between patients and control subjects. } \\
\text { Antidepressant treatment for } 5 \text { weeks reduced Glu and } \\
\text { increase Gln plasmatic levels }\end{array}$ \\
\hline Berk et al 2001 & $\begin{array}{l}\text { Platelet intracellular calcium response to } \\
\text { Glu stimulation }\end{array}$ & Greater in 15 MDD medication free patients vs. controls \\
\hline
\end{tabular}

NMDA, $N$-methyl-D-aspartate; AMPA, $\alpha$-amino-3-hydroxy-5-methyl-4-isoxazole propioniate; ACPC, 1-aminocyclopropanecarboxylic acid; ECT, electroconvulsive therapy, DCKA, dichlorokynurenic acid; mRNA, messenger ribonucleic acid; ECS, electroconvulsive shock. BDNF, brain-derived neurotrophic factor; Glx, peak on magnetic resonance spectroscopy containing glutamate, but also other compounds (i.e., not exclusively glutamate). BPD, bipolar disorder patients; MDD, major depressive disorder patients; Glu, glutamate; Gly, glycine; Gln, glutamine; MRS, magnetic resonance spectroscopy; CSF, cerebrospinal fluid. Modified and reproduced with permission from Quiroz and Manji 2002.

an excellent review). A growing body of preclinical and clinical research suggests that the NMDA class of glutamate receptors may be involved in the pathophysiology of mood disorders and the mechanism of action of antidepressants (Table 5; Figure 4). $N$-methyl-D-aspartate receptor antagonists, such as MK-801 and AP-7, and an AMPA receptor potentiator, the biarylpropylsulfonamide LY392098, have demonstrated antidepressant effects in animal models of depression, including the application of inescapable stressors, forced-swim, and tail suspensioninduced immobility tests, in learned helplessness models of depression, and in animals exposed to a chronic mild stress procedure ( $\mathrm{Li}$ et al 2001). Furthermore, antidepressant administration has been shown to affect NMDA receptor function (Nowak et al 1993, 1995b) and receptor binding profiles (Paul et al 1992). Also consistent with the putative role of the glutamatergic system in the mechanism of action of antidepressants is the fact that repeated antidepressant administration regionally alters expression of mRNA that encodes multiple NMDA receptor subunits and radioligand binding to these receptors within circumscribed areas of the CNS (Skolnick 1999).

Recently, Berman et al (2000) reported the first placebo-controlled, double-blind trial assessing the treatment effects of a single dose of the NMDA receptor antagonist ketamine in seven patients with depression. The authors reported that subjects with depression evidenced significant improvement in depressive symptoms within a short period of time ( 72 hours) after taking ketamine but not placebo. In addition, the ketamine-induced mood improvement persisted for 1-2 weeks after the infusion. In this study, treatment with ketamine was associated with transient euphoria, cognitive deficits, and greater scores on the Brief Psychiatric Rating Scale, especially the positive symptoms. Similarly, another antiglutamatergic agent, lamotrigine, was found to be effective in acute bipolar depression (Calabrese et al 1999).

Based in large part on the observation that AMPA receptor activation increases BDNF expression, Skolnick and associates have recently undertaken a series of studies investigating the putative antidepressant efficacy of AMPA receptor potentiators in models of depression (Legutko et al 2001; Li et al 2001; Skolnick et al 2001). The AMPA receptors are a subfamily of ionotropic glutamate receptors mediating fast excitatory transmission in the CNS. As with most other ligand-gated ion channels, AMPA receptors possess multiple, allosteric modulatory sites that represent targets for "fine-tuning" the activity of the receptor by pharmacologic means. In addition to their ionotropic properties, AMPA receptors have been functionally coupled to a variety of signal transduction events involving Src-family kinases, G-proteins, and the MAP kinase (Bahr et al 2002). This raises the possibility that more subtle modulation of AMPA receptors may be a useful strategy to activate MAP kinase neurotrophic cascades. One class of compounds, "AMPA receptor potentiators" (ARPs), dramatically reduces the rate of receptor desensitization and/or deactivation (Skolnick et al 2001). Several classes of ARPs have been identified, including benzothiadiazides, such as cyclothiazide; pyrrolidones, such as piracetam and aniracetam; and benzoylpiperidines, such as CX-516. Preclinical studies have shown that 
$\mathbf{A}$

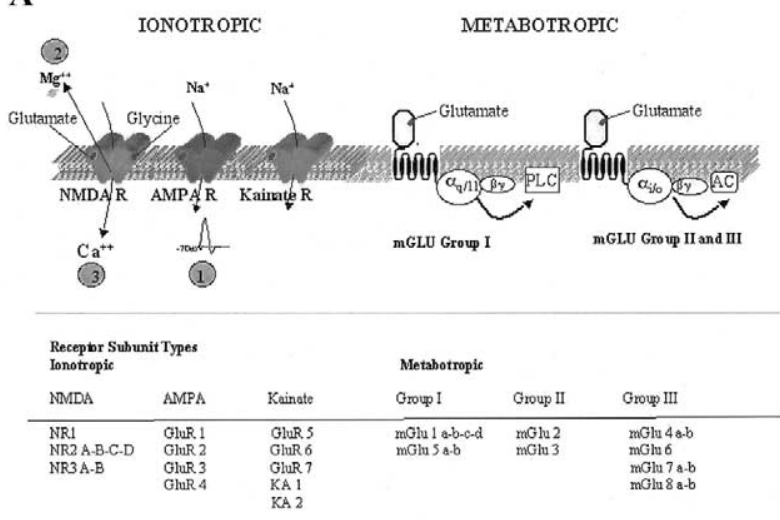

B

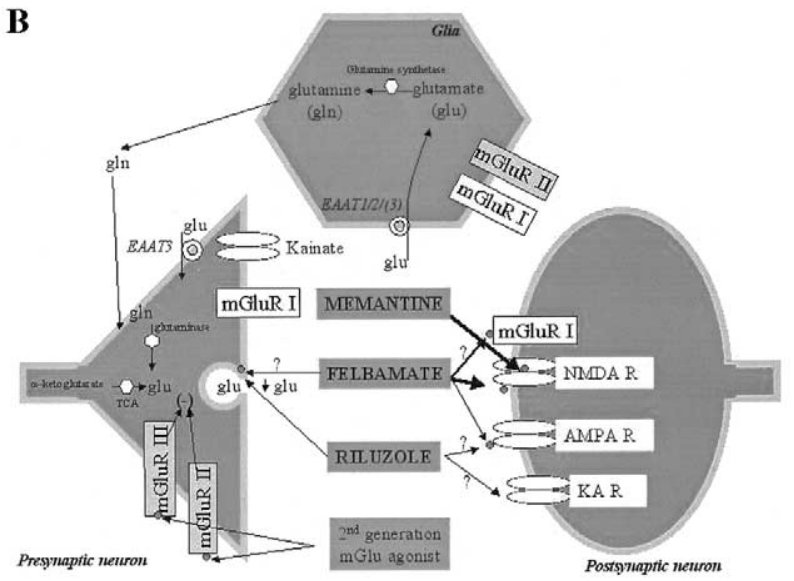

modulation of AMPA receptors with the ampakine 1-(quinoxalin-6-ylcarbonyl)piperidine (CX516) enhances MAP kinase activation and reduces the extent of synaptic and neuronal degeneration resulting from excitotoxic insults, even when infused after the insult (Bahr et al 2002). In view of the ability of structurally dissimilar ARPs to increase BDNF expression (Hayashi et al 1999; Lauterborn et al 2000; Skolnick et al 2001), studies investigating the putative efficacy of an ARP (LY392098) in animal models of depression have been investigated. These studies showed that LY392098 produced a similar reduction in the duration of immobility in the forced swim test as traditional antidepressants, suggesting that they may indeed have utility as novel antidepressants.

In other studies, CX516 has been shown to produce a marked facilitation of performance of a spatial delayednonmatch-to-sample task in rats (Hampson et al 1998). Furthermore, preliminary human studies have suggested that ampakines may have a positive memory encoding effect with respect to visual associations, recognition of odors, acquisition of a visuospatial maze, location and identity of playing cards (Ingvar et al 1997), and enhances
Figure 4. (A) The glutamatergic receptor system. Upper left: Ionotropic receptors: activation of the AMPA receptor (AMPA R) by glutamate permits the depolarization of the membrane (1). When glutamate and glycine are present, this depolarization results in the release of magnesium from the NMDA receptor (NMDA R) channel (2). Calcium also enters through the NMDA $\mathrm{R}$ pore (3). Interchange of cations additionally occurs via NMDA $\mathrm{R}$ and the Kainate glutamate receptor (KA R). Upper right: Metabotropic receptors: activation of group I metabotropic glutamate receptors (mGlu I), which are coupled with a G protein $(\mathrm{Gq} / 11)$, produces activation of phospholipase C- $\beta$ (PLC- $\beta$ ). Activation of group II metabotropic glutamate receptors (mGlu II), which are coupled with Gi or Go, produce either inhibition of adenylyl cyclase (AC) or opening of potassium channels (not shown) respectively. Bottom: The subunit composition of known receptor subtypes are shown in the figure. (B) Receptors that may represent a target for novel agents for the treatment of depression. Glutamate (glu) is synthesized in neuron from $\alpha$-ketoglutarate through the tricarboxylic acid cycle (TCA). After release, glutamate is re-uptaked by glutamate transporters (EAAT1/2/3), shown in glia and a presynaptic neuron (EAAT 3). In the glia, glutamate is catabolized to glutamine (through the enzyme glutamine synthetase), diffuses to the neurons and is then metabolized back to glutamate (through the enzyme glutaminase). The different glutamate receptors and the presumed antiglutamatergic drug sites of action are presented: Memantine is a noncompetitive antagonist at the NMDA receptor. Felbamate is a noncompetitive NMDA receptor antagonist (glycine NR1 and glutamate NR2B), an AMPA receptor antagonist, an mGlu group I receptor antagonist, and a glutamate release inhibitor (acting through blockade of $\mathrm{Ca}^{2+}$ and $\mathrm{Na}^{+}$voltage dependant channels). Riluzole is a glutamate release inhibitor (acting through blockade of $\mathrm{Ca}^{2+}$ and $\mathrm{Na}^{+}$voltage dependant channels), a $\mathrm{GABA}_{\mathrm{A}}$ agonist and probably an AMPA and Kainate antagonist. The sites for second-generation mGlu group II and III receptor agonist is also depicted. AMPA, $\alpha$-amino-3-hydroxy-5-methylisoxazole propionate; NMDA, $N$-methyl-D-aspartate; GABA, $\gamma$-aminobutyric acid. Figure 4B modified and reproduced with permission from Zarate et al 2003.

delayed recall in older individuals (Lynch et al 1997). Finally, in very preliminary studies of schizophrenic patients, CX516 was added to clozapine in 4-week, placebo-controlled, dose-finding and fixed-dose trials and was suggested to exert beneficial effects in measures of attention and memory (Goff et al 2001). An investigation of CNS-penetrant AMPA modulating agents in the treatment of depression is clearly warranted.

\section{Clinical Investigations of the Glutamatergic Signaling Modifiers in the Treatment of Depression}

Several novel glutamatergic strategies are currently being investigated in the treatment of depression (for a complete review, see Zarate et al 2003). 
Riluzole, a 2-amino-6-trifluoromethoxy belonging to the benzothiazole class, is a neuroprotective agent with anticonvulsant properties. The U.S Food and Drug Administration (FDA), the Committee for Proprietary Medicinal Products in Europe, and the Ministry of Health and Welfare in Japan have approved it for the treatment of amyotrophic lateral sclerosis. It acts by inhibition of the glutamate release, blocking presynaptic calcium and sodium ion channels, by inhibition of the voltage-dependent sodium channels in mammalian CNS neurons, and by inhibition of postsynaptic actions by indirect mechanisms. It has been shown to have neuroprotective properties in animal models of Parkinson's disease, dementia, ischemia, and traumatic CNS injury. Although is well tolerated, side effects include nausea, vomiting, anorexia, asthenia, dizziness, and circumoral paresthesia; $10 \%$ elevated alanine aminotransferase levels and granulocytopenia that it is a rare event. A pilot study is underway at the National Institute of Mental Health, investigating the putative antidepressant effects of riluzole in major depression (Zarate et al 2003).

Felbamate, a 2-phenyl-1, 3-propanediol dicarbamate, is a broad-spectrum anticonvulsant chemically related to meprobamate. It is FDA approved as monotherapy and adjunctive therapy in adults with partial-onset epilepsy. It acts as a noncompetitive NMDA antagonist (NR1-2B), by inhibition of AMPA/kainite and dihydropyridine-sensitive calcium channels, and enhancing $\mathrm{GABA}_{\mathrm{A}}$ activity. It has been shown to have neuroprotective properties in hypoxia-ischemia models, hippocampal traumatic injury models, and in culture from excitotoxic insult. Its most common side effects include nausea, dizziness, vomiting, anorexia, and weight loss. Some idiosyncratic events are aplastic anemia (127 per million per year) and hepatic toxicity (1:18,000-1:25,000). Studies are currently underway, investigating the potential antidepressant efficacy of felbamate in treatment-refractory depressed patients (Zarate et al 2003).

Memantine, a 1-amino-3, 5-dimethyladamantane of the adamantine class has anticonvulsant and neuroprotective properties and dopaminergic effects in vitro. Memantine has been used since 1978 and is approved in Germany for mild and moderate cerebral performance disorders with concentration and memory disorders, loss of interest and drive, premature fatigue, and depressive mood (dementia syndrome); cerebral and spinal spasticity; and Parkinson's disease. It acts as a modulator of glutamatergic neurotransmission: in the states of a reduced glutamate release, after degeneration of neurons, memantine results in an improvement in signal transmission and activation of neurons; in the state of a massive glutamate release (e.g., ischemia), memantine blocks NMDA receptors that mediate the excitotoxic action of glutamate on neurons. It is well tolerated, and side effects include dizziness, internal and motoric restlessness and agitation, fatigue, congestion in the head, and nausea. Only a few isolated cases of psychosis and cognitive deficits have been reported with its use. A large, double-blind, placebo-controlled trial is underway, examining the efficacy of memantine in the treatment of depression (Zarate et al 2003).

\section{The HPA Axis as a Target for the Development of Novel Therapeutics}

As discussed above, there is a growing appreciation that abnormalities of the HPA axis may play a role in mediating the phenotypic expression of certain depressive states (Gold and Chrousos 2002), and not surprisingly, there is increasing interest in targeting this system for the development of novel therapeutics. Novel therapeutic targets for the treatment of dysfunction of the HPA system include dehydroepiandrosterone (DHEA), steroid synthesis inhibitors, CRH antagonists, and glucocorticoid antagonists (McQuade and Young 2000). Treatment with glucocorticoid synthesis inhibitors (e.g., ketoconazole) has been observed to rapidly ameliorate depression in treatmentresistant depression (Reus and Wolkowitz 2001). Clinical studies are also investigating the putative efficacy of the GR antagonist, mifepristone, for the treatment of depression. Mifepristone is a potent antagonist of GR (but not $\mathrm{MR}$ ), as well as progesterone receptors. Empirical evidence of its efficacy in rapid treatment of depression in patients with Cushing's disease inspired further study in primary affective disorders. There are a number of mechanistic considerations suggesting that a more extensive investigation of the potential efficacy of mifepristone to protect against the negative effects of excessive GR signaling in depression is warranted (Gold et al 2002). Among them, mifepristone may antagonize the effects of excessive cortisol on PFC and hippocampal structure and function (which leads to disinhibition of the HPA axis), thereby interrupting a maladaptive feed-forward mechanism in severely depressed patients. Additionally, the amygdala inhibits the PFC and activates both the HPA axis and brainstem noradrenergic nuclei (including the locus coeruleus); thus, mifepristone, by blocking amygdala GR receptors, may attenuate the deleterious effects of amygdala hyperactivity on the PFC, hippocampus, and brainstem sites.

Preliminary data indicate that mifepristone may be rapidly and robustly effective in the treatment of psychotic depression (Belanoff et al 2001), the subtype of depression most clearly associated with HPA axis hyperactivity. Belanoff and colleagues at Stanford observed improvement in mood and psychosis in a crossover trial after 4 
days of treatment $(n=5)$. Moreover, an open dose-finding study of $50 \mathrm{mg}, 600 \mathrm{mg}$, and $1200 \mathrm{mg}$ of mifepristone for 7 days in psychotic depression $(n=30)$ observed a $40 \%-50 \%$ response rate (>50\% improvement) in the two high-dose groups and a $50 \%$ or greater response on the positive symptoms subscale of the Brief Psychiatric Rating Scale in 12 of 19 subjects (Belanoff et al 2002). A multicenter, double-blind trial is now underway with mifepristone in psychotic depression. Pilot data in a crossover bipolar depression study was recently presented as a meeting abstract and again suggested functional improvement after only brief therapy (Young, unpublished data). In ongoing studies, Young and colleagues propose to examine DHEA-S and cortisol levels, as well as mood and psychosis changes and neuropsychological function with mifepristone. Preliminary data indicate that bipolar subjects show a significant improvement in verbal fluency after mifepristone in preliminary analysis, and although mood data has not been analyzed, at least some subjects have shown clinical improvement.

A double-blind, placebo-controlled study of mifepristone in inpatients with bipolar depression is being undertaken at the National Institute of Mental Health. Subjects will have endocrine and cognitive evaluation, followed by randomization to 8 days of mifepristone versus placebo, followed by blind crossover to the opposite arm. Rapid antidepressant response in bipolar depression with mifepristone could represent an important new strategy, given the problems with cycle induction and mania with standard antidepressants in this condition.

Further preclinical study is also underway investigating small-molecule $\mathrm{CRH}$ antagonists for the treatment of depression. The orally active CRH antagonist antalarmin significantly reduces fear and anxiety responses in nonhuman primates (Habib et al 2000) and may be a candidate for further development. Because standard antidepressants appear to take several weeks to suppress CRH expression and release, the blockade of CRH receptors has been proposed as a rapid antidepressant strategy (Zobel et al 2000). Several pharmaceutical companies have developed substituted pyrimidine small-molecule CRH antagonists (for review see Owens and Nemeroff 1999). In an openlabel, dose escalation study by Zobel et al (2000), 24 subjects with major depression received either a high dose or a low dose of the CRH antagonist R121919. Improvement of scores on the Hamliton Rating Scales for Depression/Anxiety was significant and similar to historical control data with paroxetine under study conditions. Furthermore, in the high-dose group $(n=10) 8 / 10$ subjects analyzed were responders and 6/10 were remitters, compared with 5/10 responders and 3/10 remitters in the low-dose group. Patients had an abrupt worsening of mood symptoms when the antagonist was discontinued, suggesting that response was pharmacologically contingent; however, this was a "completer" rather than an intention-totreat analysis, and four subjects were removed from analysis due to drop-out, one of whom was dropped due to worsening symptomatology and suicidality. R121919, although generally well tolerated, was dropped from clinical development due to hepatotoxicity but provides proof of concept in a preliminary fashion for this strategy.

\section{Strategies to Potentiate the CREB/BDNF/ Bcl-2 Cascade for the Treatment of Depressive Disorders}

There is a growing body of data suggesting that agents that directly modulate the CREB/BDNF/bcl-2 cascade may have utility for the treatment of mood disorders (D'Sa and Duman 2002; Nestler et al 2002; Quiroz and Manji 2002). One approach is to use an inhibitor of phosphodiesterase (PDE), the enzyme responsible for the breakdown of cAMP. In this context, Takahashi et al (1999) demonstrated that chronic antidepressant administration increases the expression of cAMP-specific PDE4A and PDE4B isoforms; these effects likely represent a compensatory "counter-regulatory" response to the chronic antidepressants (Nibuya et al 1996). These data suggest that PDE4A and PDE4B may be relevant targets for development of agents that possess antidepressant effects, either as monotherapy or in combination with agents that increase intrasynaptic monoamine levels, because of the possible synergism of effects on the cAMP cascade. Preclinical studies conducted to date do support the potential utility of PDE4 inhibitors in the treatment of depressive disorders. Thus, long-term administration of PDE4 inhibitors increases the expression of CREB and BDNF in the hippocampus of rats (Asanuma et al 1996; Fujimaki et al 2000), and PDE inhibitors have antidepressant-like effects in behavioral models (Griebel et al 1991; O’Donnell 1993; Wachtel and Schneider 1986).

Indeed, the idea that PDE inhibitors may have potential antidepressant activity is not a new one: it was initially proposed by Wachtel in the early 1980s (Wachtel and Schneider 1986). In the 1980s and early 1990s, a number of open (Zeller et al 1984) and controlled clinical trials (Bertolino et al 1988; Bobon et al 1988; Fleischhacker et al 1992; Hebenstreit et al 1989) demonstrated that rolipram, a specific inhibitor of the high-affinity cAMP PDE4, may have antidepressant efficacy in depressed patients. In addition, there is evidence that rolipram may have a faster onset of response compared with the standard antidepressants. In the clinical study by Horowski and Sastre-YHernandez (1985), a rapid antidepressant effect to rolipram was reported to occur within the first 12 hours to 10 
days, and another study (Zeller et al 1984) reported an antidepressant effect only after 2-4 days of treatment; however, in a randomized, double-blind comparative trial of rolipram versus imipramine, Hebenstreit et al (1989) found that imipramine was more effective than rolipram, though both were beneficial. Further, after a controlled study, Scott et al (1991) concluded that amitriptyline was more effective than rolipram in the treatment of depressed inpatients. Though the overall literature on the use of rolipram is suggestive that PDE inhibitors may have antidepressant efficacy and may have a faster onset of action, the potential use of rolipram for depression was limited because of side effects such as nausea and emesis.

Recent studies demonstrating that PDE4 is expressed in inflammatory cells, such as eosinophils, and that inhibition of PDE4 down-regulates the inflammatory response have generated renewed excitement about the possible utility of this class of agents in the treatment of diseases such as asthma, chronic obstructive pulmonary disease, rheumatoid arthritis, Crohn's disease, and multiple sclerosis (Dyke and Montana 2002; Huang et al 2001). Secondgeneration compounds with markedly improved tolerability are rapidly being developed (Dyke and Montana 2002; Huang et al 2001), and it is anticipated that the availability of CNS-penetrant PDE4 inhibitors may lead to the development of a novel class of antidepressants.

Human phase I/II trials of recombinant methionyl human BDNF have already been undertaken, wherein the BDNF was administered by intrathecal infusion to patients with amyotrophic lateral sclerosis (Ochs et al 2000). Unfortunately, side effects such as sensory symptoms, including paraesthesias or a sense of warmth, sleep disturbance, dry mouth, agitation, and other behavioral effects were encountered at higher doses, precluding further study.

An increasing number of strategies are being investigated to develop small-molecule switches for proteinprotein interactions, which have the potential to regulate the activity of growth factors, MAP kinases cascades, and interactions between homo- and heterodimers of the bcl-2 family of proteins. In view of the robust effects of bcl-2 on neurite sprouting, neurite outgrowth, and axonal regeneration (Chen and Tonegawa 1998; Chen et al 1997; Chierzi et al 1999; Holm et al 2001; Oh et al 1996), and protection against the deleterious CNS effects of severe stress (DeVries et al 2001), it is quite possible that bcl-2 enhancers will have utility in the treatment of depressive disorders. Indeed, it is quite possible that lithium's ability to robustly upregulate bcl-2 may play a role in its antidepressant potentiating effects. It is also noteworthy that pramipexole also upregulates bcl-2 in several brain areas (Takata et al 2000) and has been shown to exert antidepressant effects in preliminary studies (Sporn et al 2000). Although the dopamine agonistic effects of pramipexole may clearly also contribute to its purported antidepressant effects, its robust neurotrophic effects suggest that it may have broader utility as an antidepressant potentiator. In this context, ongoing longitudinal studies at the National Institute of Mental Health are investigating pramipexole's antidepressant and neurotrophic effects with the use of serial magnetic resonance spectroscopy measurements of NAA and volumetric MRIs.

\section{Concluding Remarks}

As discussed, there is a considerable body of evidence, both conceptual and experimental, suggesting that impairments in neuroplasticity and cellular resilience may play an important role in the pathophysiology of recurrent mood disorders. Furthermore, we contend that for many refractory depression patients, new drugs simply mimicking many "traditional" drugs that directly or indirectly alter neurotransmitter levels and those that bind to cell surface receptors may be of limited benefit. This is because such strategies implicitly assume that the target circuits are functionally intact and that altered synaptic activity will thus be transduced to modify the postsynaptic "throughput" of the system; however, the evidence presented here suggests that, in addition to neurochemical changes, many patients also have pronounced structural alterations (e.g., reduced spine density, neurite retraction, overall neuropil reductions) in critical neuronal circuits. Thus, optimal treatment may only be attained by providing both trophic and neurochemical support; the trophic support would be envisioned as enhancing and maintaining normal synaptic connectivity, thereby allowing the chemical signal to reinstate the optimal functioning of critical circuits necessary for normal affective functioning. Indeed, preliminary studies have suggested that regional structural brain changes in patients with mood disorders may be associated not only with illness severity/duration, but also with altered treatment response to pharmacologic agents and ECT (Pillay et al 1997; Vakili et al 2000).

The evidence also suggests that, somewhat akin to the treatment of conditions like hypertension and diabetes, early and potentially sustained treatment may be necessary to adequately prevent many of the deleterious long-term sequellae associated with mood disorders. Although data suggest that hippocampal atrophy in depression may be related to illness duration (Sheline et al 1999), it is presently not clear whether the volumetric and cellular changes that have been observed in other brain areas (most notably frontal cortex) are related to affective episodes per 


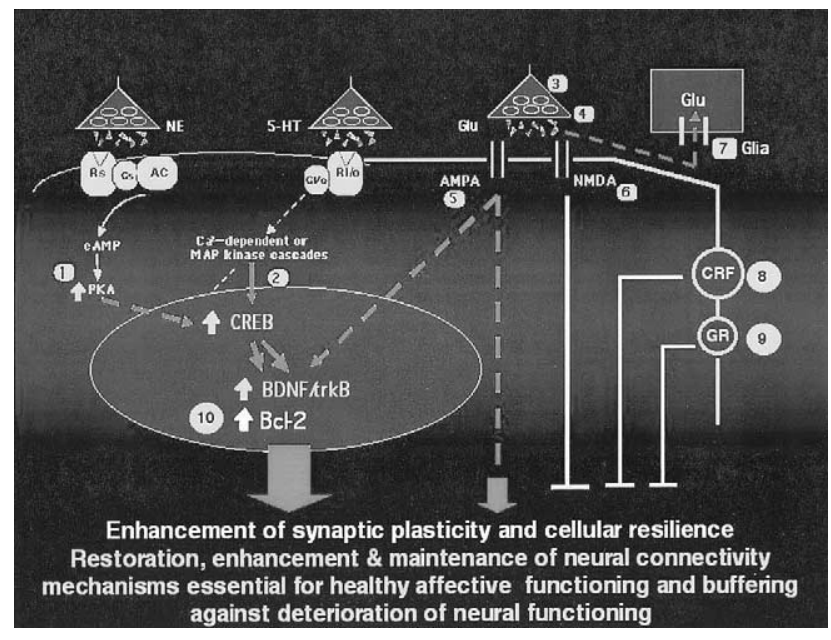

Figure 5. Plasticity regulators as targets for the development of novel agents for the treatment of depression. This figure depicts the multiple targets by which neuroplasticity and cellular resilience can be increased in mood disorders. Genetic/neurodevelopmental factors, repeated affective episodes (and likely elevations of glucocorticoids), and illness progression may all contribute to the impairments of cellular resilience, volumetric reductions, and cell death/ atrophy observed in mood disorders. Bcl-2 attenuates apoptosis by sequestering proforms of death-driving cysteine proteases (called caspases), by preventing the release of mitochondrial apoptogenic factors, such as calcium, cytochrome c, and AIF (apoptosis-inducing factor) into the cytoplasm, and by enhancing mitochondrial calcium uptake. Antidepressants regulate the expression of BDNF, and its receptor TrkB. Both TrkA and TrkB utilize the PI-3-kiase/Akt and ERK MAP kinase pathways to bring about their neurotrophic effects. The ERK MAP kinase cascade also increases the expression of bcl-2 via its effects on CREB. 1) Phosphodiesterase inhibitors increase the levels of pCREB; 2) MAP kinase modulators increase the expression of the major neurotrophic protein, bcl-2; 3) mGluR II/III agonists modulate the release of excessive levels of glutamate; 4) drugs such as riluzole and felbamate act on $\mathrm{Na}+$ channels to attenuate glutamate release; 5) AMPA potentiators upregulate the expression of BDNF; 6) NMDA antagonists like memantine enhance plasticity and cell survival; 7) novel drugs to enhance glial release of trophic factors and clear excessive glutamate may have utility for the treatment of depressive disorders; 8) corticotropin release hormone (CRH) and 9) glucocorticoid antagonists attenuate the deleterious effects of hypercorisolemia and CRH antagonists may exert other beneficial effects in the treatment of depression via non-HPA mechanisms; 10) agents which upregulate bcl-2 (e.g., pramipexole) would be postulated to have considerable utility in the treatment of depression and other stress-related disorders. NE, norepinephrine; 5-HT, serotonin; Glu, glutamine; BDNF, brain-derived neurotrophic factor; ERK, extracellular response kinase; MAP, mitogen-activated protein; CREB, cyclic adenosine monophosphate response element-binding protein; mGluR, metabotropic glutamate receptor; AMPA, alpha-amino3-hydroxy-5-methylisoxazole propionate; NMDA, $N$-methyl-Daspartate; GR, glucocorticoid receptor; CRF, corticotropin release factor; PKA, protein kinase A. se. Indeed, some studies have observed reduced gray matter volumes and enlarged ventricles in mood disordered patients at first/early onset (Hirayasu et al 1999; Strakowski et al 1993). At this point, it is unclear whether the regional cellular atrophy in mood disorders occurs owing to the magnitude and duration of biochemical perturbations, an enhanced vulnerability to the deleterious effects of these perturbations (due to genetic factors and/or early-life events), or a combination thereof. In this context, a growing body of data has demonstrated that neonatal stress can have a major impact on brain development, in particular by bringing about persistent changes in $\mathrm{CRH}-$ containing neurons, the HPA axis, the serotonergic system, the noradrenergic system, and the sympathetic nervous system (Graham et al 1999). Furthermore, although there are undoubtedly genetic contributions (both susceptibility and protective) to the impact of neonatal stesses on brain development, it is noteworthy that recent studies have also demonstrated nongenomic transmission across generations of not only maternal behavior but also stress responses (Francis et al 1999). The possibility that these neurochemical alterations produces a state of neuroendangerment (see above), which contributes to the subsequent development of morphologic brain changes in adulthood, requires further investigation. A growing body of data is also demonstrating a relationship (potentially bidirectional) between mood disorders and cardiovascular/cerebrovascular disease, suggesting that at least in a subset of patients (perhaps those who have been "primed" for impairments of cellular resiliency by genetic factors), CNS vascular insufficiency may be a contributory factor (Doraiswamy et al 1999; Musselman et al 1998; Steffens and Krishnan 1998; Steffens et al 1999).

In conclusion, emerging results from a variety of clinical and preclinical experimental and naturalistic studies suggest that a reconceptualization as to the pathophysiology, course, and optimal long-term treatment of recurrent mood disorders may be warranted. Optimal long-term treatment for these severe illnesses may require the early use of agents that enhance neuroplasticity and cellular resilience. As discussed, there are a number of pharmacologic "plasticity enhancing" strategies that may be of considerable utility in the treatment of mood disorders (see Figure 5). Among the most immediate ones are NMDA antagonists, glutamate release-reducing agents, AMPA potentiators, cAMP PDE inhibitors, and GR antagonists. An increasing number of strategies are being investigated to develop small-molecule agents to regulate the activity of growth factors, MAP kinases cascades, and the bcl-2 family of proteins; this progress holds much promise for the development of novel therapeutics for the long-term treatment of severe, refractory mood disorders and for improving the lives of millions. 
Aspects of this work were presented at the conference, "Difficult-toTreat Depression," held April 21-22, 2002 in San Francisco, California. The conference was sponsored by the Society of Biological Psychiatry through an unrestricted grant provided by Eli Lilly and Company.

\section{References}

Aberg-Wistedt A, Hasselmark L, Stain-Malmgren R, Aperia B, Kjellman BF, Mathe AA (1998): Serotonergic 'vulnerability' in affective disorder: A study of the tryptophan depletion test and relationships between peripheral and central serotonin indexes in citalopram-responders. Acta Psychiatr Scand 97:374-380.

Adams JM, Cory S (1998): The Bcl-2 protein family: Arbiters of cell survival. Science 281:1322-1326.

Altamura C, Maes M, Dai J, Meltzer HY (1995): Plasma concentrations of excitatory amino acids, serine, glycine, taurine and histidine in major depression. Eur Neuropsychopharmacol 5(suppl):71-75.

Altamura CA, Mauri MC, Ferrara A, Moro AR, D'Andrea G, Zamberlan F (1993): Plasma and platelet excitatory amino acids in psychiatric disorders. Am J Psychiatry 150:17311733.

Altshuler LL, Casanova MF, Goldberg TE, Kleinman JE (1990): The hippocampus and parahippocampus in schizophrenia, suicide, and control brains. Arch Gen Psychiatry 47:10291034.

Asanuma M, Nishibayashi S, Iwata E, Kondo Y, Nakanishi T, Vargas MG, et al (1996): Alterations of cAMP response element-binding activity in the aged rat brain in response to administration of rolipram, a cAMP-specific phosphodiesterase inhibitor. Brain Res Mol Brain Res 41:210-215.

Auer DP, Putz B, Kraft E, Lipinski B, Schill J, Holsboer F (2000): Reduced glutamate in the anterior cingulate cortex in depression: An in vivo proton magnetic resonance spectroscopy study. Biol Psychiatry 47:305-313.

Bahr BA, Bendiske J, Brown QB, Munirathinam S, Caba E, Rudin M, et al (2002): Survival signaling and selective neuroprotection through glutamatergic transmission. Exp Neurol 174:37-47.

Baumann B, Danos P, Krell D, Diekmann S, Leschinger A, Stauch R, et al (1999): Reduced volume of limbic systemaffiliated basal ganglia in mood disorders: preliminary data from a postmortem study. J Neuropsychiatry Clin Neurosci $11: 71-78$

Belanoff J, Flores B, Kalezhan M, Sund B, Schatzberg A (2001): Rapid reversal of psychotic depression using mifepristone. J Clin Psychopharmacol 21:516-521.

Belanoff JK, Rothschild A, Cassidy F, DeBattista C, Baulieu EE, Schold C, et al (2002): An open label trial of C-1073 (mifepristone) for psychotic major depression. Biol Psychiatry 52:386-392.

Benes FM, Kwok EW, Vincent SL, Todtenkopf MS. (1998): A reduction of nonpyramidal cells in sector CA2 of schizophrenics and manic depressives. Biol Psychiatry 44:88-97.

Benes FM, Vincent SL, Todtenkopf M (2001): The density of pyramidal and nonpyramidal neurons in anterior cingulate cortex of schizophrenic and bipolar subjects. Biol Psychiatry 50:395-406.
Berk M, Plein H, Ferreira D (2001): Platelet glutamate receptor supersensitivity in major depressive disorder. Clin Neuropharmacol 24:129-132.

Berman RM, Cappiello A, Anand A, Oren DA, Heninger GR, Charney DS, et al (2000): Antidepressant effects of ketamine in depressed patients. Biol Psychiatry 47:351-354.

Bertolino A, Crippa D, di Dio S, Fichte K, Musmeci G, Porro V, et al (1988): Rolipram versus imipramine in inpatients with major, "minor" or atypical depressive disorder: A doubleblind double-dummy study aimed at testing a novel therapeutic approach. Int Clin Psychopharmacol 3:245-253.

Beyer JL, Krishnan KR (2002): Volumetric brain imaging findings in mood disorders. Bipolar Disord 4:89-104.

Bobon D, Breulet M, Gerard-Vandenhove MA, Guiot-Goffioul F, Plomteux G, Sastre-y-Hernandez M, et al (1988): Is phosphodiesterase inhibition a new mechanism of antidepressant action? A double blind double-dummy study between rolipram and desipramine in hospitalized major and/or endogenous depressives. Eur Arch Psychiatry Neurol Sci 238:2-6.

Bonni A, Brunet A, West AE, Datta SR, Takasu MA, Greenberg ME (1999): Cell survival promoted by the Ras-MAPK signaling pathway by transcription-dependent and -independent mechanisms. Science 286:1358-1362.

Bouras C, Kovari E, Hof PR, Riederer BM, Giannakopoulos P (2001): Anterior cingulate cortex pathology in schizophrenia and bipolar disorder. Acta Neuropathol (Berl) 102:373-379.

Bouron A, Chatton JY (1999): Acute application of the tricyclic antidepressant desipramine presynaptically stimulates the exocytosis of glutamate in the hippocampus. Neuroscience 90:729-736.

Bowley MP, Drevets WC, Ongur D, Price JL (2002): Low glial numbers in the amygdala in major depressive disorder. Biol Psychiatry 52:404-412.

Boyer PA, Skolnick P, Fossom LH (1998): Chronic administration of imipramine and citalopram alters the expression of NMDA receptor subunit mRNAs in mouse brain. A quantitative in situ hybridization study. J Mol Neurosci 10:219233.

Brunson KL, Eghbal-Ahmadi M, Bender R, Chen Y, Baram TZ (2001): Long-term, progressive hippocampal cell loss and dysfunction induced by early-life administration of corticotropin-releasing hormone reproduce the effects of early-life stress. Proc Natl Acad Sci U S A 98:8856-8861.

Calabrese JR, Bowden CL, Sachs GS, Ascher JA, Monaghan E, Rudd GD (1999): A double-blind placebo-controlled study of lamotrigine monotherapy in outpatients with bipolar I depression. Lamictal 602 Study Group. J Clin Psychiatry 60:79-88.

Cameron HA, McKay RD (1999): Restoring production of hippocampal neurons in old age. Nat Neurosci 2:894-897.

Carmelli D, Reed T, DeCarli C (2002): A bivariate genetic analysis of cerebral white matter hyperintensities and cognitive performance in elderly male twins. Neurobiol Aging 23:413-420.

Castillo M, Kwock L, Courvoisie H, Hooper SR (2000): Proton MR spectroscopy in children with bipolar affective disorder: Preliminary observations. AJNR Am J Neuroradiol 21:832838.

Chemerinski E, Robinson RG (2000): The neuropsychiatry of stroke. Psychosomatics 41:5-14. 
Chen AC, Shin KH, Duman RS, Sanacora G (2001a): ECSInduced mossy fiber sprouting and BDNF expression are attenuated by ketamine pretreatment. J ECT Mar 17:27-32.

Chen AC, Shirayama Y, Shin KH, Neve RL, Duman RS (2001b): Expression of the cAMP response element binding protein (CREB) in hippocampus produces an antidepressant effect. Biol Psychiatry 49:753-762.

Chen B, Dowlatshahi D, MacQueen GM, Wang JF, Young LT (2001): Increased hippocampal BDNF immunoreactivity in subjects treated with antidepressant medication. Biol Psychiatry 50:260-265.

Chen DF, Schneider GE, Martinou JC, Tonegawa S (1997): $\mathrm{Bcl}-2$ promotes regeneration of severed axons in mammalian CNS. Nature 385:434-439.

Chen DF, Tonegawa S (1998): Why do mature CNS neurons of mammals fail to re-establish connections following injuryfunctions of bcl-2. Cell Death Differ 5:816-822.

Chen G, Huang LD, Zeng WZ, Manji HK (2001): Mood stabilizers regulate cytoprotective and mRNA-binding proteins in the brain: Long-term effects on cell survival and transcript stability. Int J Neuropsychopharmacol 4:47-64.

Chen G, Rajkowska G, Du F, Seraji-Bozorgzad N, Manji HK (2000): Enhancement of hippocampal neurogenesis by lithium. J Neurochem 75:1729-1734.

Chen G, Zeng WZ, Yuan PX, Huang LD, Jiang YM, Zhao ZH, et al (1999): The mood-stabilizing agents lithium and valproate robustly increase the levels of the neuroprotective protein bcl-2 in the CNS. J Neurochem 72:879-882.

Chierzi S, Strettoi E, Cenni MC, Maffei L (1999): Optic nerve crush: Axonal responses in wild-type and bcl-2 transgenic mice. J Neurosci 19:8367-8376.

Cotter D, Mackay D, Chana G, Beasley C, Landau S, Everall IP (2002): Reduced neuronal size and glial cell density in area 9 of the dorsolateral prefrontal cortex in subjects with major depressive disorder. Cereb Cortex 12:386-394.

Cotter D, Mackay D, Landau S, Kerwin R, Everall I (2001): Reduced glial cell density and neuronal size in the anterior cingulate cortex in major depressive disorder. Arch Gen Psychiatry 58:545-553.

Coyle JT, Schwarcz R (2000): Mind glue: Implications of glial cell biology for psychiatry. Arch Gen Psychiatry 57:90-93.

Crane G (1959): Cycloserine as an antidepressant agent. Am J Psychiatry 115:1025-1026.

Czeh B, Michaelis T, Watanabe T, Frahm J, de Biurrun G, van Kampen M, et al (2001): Stress-induced changes in cerebral metabolites, hippocampal volume, and cell proliferation are prevented by antidepressant treatment with tianeptine. Proc Natl Acad Sci U S A 98:12796-12801.

Delgado PL, Miller HL, Salomon RM, Licinio J, Krystal JH, Moreno FA, et al (1999): Tryptophan-depletion challenge in depressed patients treated with desipramine or fluoxetine: Implications for the role of serotonin in the mechanism of antidepressant action. Biol Psychiatry 46:212-220.

Delgado PL, Price LH, Miller HL, Salomon RM, Licinio J, Krystal JH, et al (1991): Rapid serotonin depletion as a provocative challenge test for patients with major depression: Relevance to antidepressant action and the neurobiology of depression. Psychopharmacol Bull 27:321-330. de Montigny C, Cournoyer G, Morissette R, Langlois R, Caille G (1983): Lithium carbonate addition in tricyclic antidepressant-resistant unipolar depression. Correlations with the neurobiologic actions of tricyclic antidepressant drugs and lithium ion on the serotonin system. Arch Gen Psychiatry 40:1327-1334.

DeVries AC, Joh HD, Bernard O, Hattori K, Hurn PD, Traystman RJ, et al (2001): Social stress exacerbates stroke outcome by suppressing Bcl-2 expression. Proc Natl Acad Sci U S A 98:11824-11828.

Dixon JF, Hokin LE (1998): Lithium acutely inhibits and chronically up-regulates and stabilizes glutamate uptake by presynaptic nerve endings in mouse cerebral cortex. Proc Natl Acad Sci U S A 95:8363-8368.

Doraiswamy PM, MacFall J, Krishnan KR, O'Connor C, Wan X, Benaur M, et al (1999): Magnetic resonance assessment of cerebral perfusion in depressed cardiac patients: Preliminary findings. Am J Psychiatry 156:1641-1643.

Drevets 2000Drevets WC (2000): Neuroimaging studies of mood disorders. Biol Psychiatry 48:813-829.

Drevets WC (2001): Neuroimaging and neuropathological studies of depression: Implications for the cognitive-emotional features of mood disorders. Curr Opin Neurobiol 11:240249.

D'Sa C, Duman R (2002): Antidepressants and neuroplasticity. Bipolar Disord 4:183.

Du J, Gould TD, Manji HK (in press): Neurotrophic Signaling in Mood Disorders. In Finkel T and Gutkind G, editors. Signal Transduction and Human Health. New York, NY: John Wiley and Sons.

Duman RS, Malberg J, Thome J (1999): Neural plasticity to stress and antidepressant treatment. Biol Psychiatry 46:11811191.

Dyke HJ, Montana JG (2002): Update on the therapeutic potential of PDE4 inhibitors. Expert Opin Investig Drugs 11:1-13.

Eriksson PS, Perfilieva E, Bjork-Eriksson T, Alborn AM, Nordborg C, Peterson DA, et al (1998): Neurogenesis in the adult human hippocampus. Nat Med 4:1313-1317.

Finkbeiner S (2000): CREB couples neurotrophin signals to survival messages. Neuron 25:11-14.

Fleischhacker WW, Hinterhuber H, Bauer H, Pflug B, Berner P, Simhandl C, et al (1992): A multicenter double-blind study of three different doses of the new cAMP-phosphodiesterase inhibitor rolipram in patients with major depressive disorder. Neuropsychobiology 26:59-64.

Francis D, Diorio J, Liu D, Meaney MJ (1999): Nongenomic transmission across generations of maternal behavior and stress responses in the rat. Science 286:1155-1158.

Fryer RH, Kaplan DR, Feinstein SC, Radeke MJ, Grayson DR, Kromer LF (1996): Developmental and mature expression of full-length and truncated TrkB receptors in the rat forebrain. J Comp Neurol 374:21-40.

Fujimaki K, Morinobu S, Duman RS (2000): Administration of a cAMP phosphodiesterase 4 inhibitor enhances antidepressant-induction of BDNF mRNA in rat hippocampus. Neuropsychopharmacology 22:42-51.

Gass P, Kretz O, Wolfer DP, Berger S, Tronche F, Reichardt $\mathrm{HM}$, et al (2000): Genetic disruption of mineralocorticoid receptor leads to impaired neurogenesis and granule cell 
degeneration in the hippocampus of adult mice. $E M B O$ Rep $1: 447-451$.

Gesing A, Bilang-Bleuel A, Droste SK, Linthorst AC, Holsboer F, Reul JM (2001): Psychological stress increases hippocampal mineralocorticoid receptor levels: Involvement of corticotropin-releasing hormone. J Neurosci 21:4822-4829.

Goff DC, Leahy L, Berman I, Posever T, Herz L, Leon AC, et al (2001): A placebo-controlled pilot study of the ampakine CX516 added to closapine in schizophrenia. J Clin Psychopharmacol 21:484-487.

Goggi J, Pullar IA, Carney SL, Bradford HF (2002): Modulation of neurotransmitter release induced by brain-derived neurotrophic factor in rat brain striatal slices in vitro. Brain Res 941:34-42.

Gold PW, Drevets WC, Charney DS (2002): New insights into the role of cortisol and the glucocorticoid receptor in severe depression. Biol Psychiatry 52:381-385.

Gold PW, Chrousos GP (2002): Organization of the stress system and its dysregulation in melancholic and atypical depression: High vs low CRH/NE states. Mol Psychiatry 7:254-275.

Gonzalez M, Ruggiero FP, Chang Q, Shi YJ, Rich MM, Kraner $S$, et al (1999): Disruption of Trkb-mediated signaling induces disassembly of postsynaptic receptor clusters at neuromuscular junctions. Neuron 24:567-583.

Gould E, Allan MD, McEwen BS (1990): Dendritic spine density of adult hippocampal pyramidal cells is sensitive to thyroid hormone. Brain Res 525:327-329.

Gould E, Tanapat P, Rydel T, Hastings N (2000): Regulation of hippocampal neurogenesis in adulthood. Biol Psychiatry 48:715-720.

Gould E, Woolley CS, McEwen BS (1991): The hippocampal formation: Morphological changes induced by thyroid, gonadal and adrenal hormones. Psychoneuroendocrinology $16: 67-84$

Gould T, Manji H (2002): Signaling networks in the pathophysiology \& treatment of mood disorders. J Psychosom Res 53:687-697.

Graham YP, Heim C, Goodman SH, Miller AH, Nemeroff CB (1999): The effects of neonatal stress on brain development: Implications for psychopathology. Dev Psychopathol 11:545-565.

Griebel G, Misslin R, Vogel E, Bourguignon JJ (1991): Behavioral effects of rolipram and structurally related compounds in mice: Behavioral sedation of cAMP phosphodiesterase inhibitors. Pharmacol Biochem Behav 39:321-323.

Habib KE, Weld KP, Rice KC, Pushkas J, Champoux M, Listwak S, et al (2000): Oral administration of a corticotropin-releasing hormone receptor antagonist significantly attenuates behavioral, neuroendocrine, and autonomic responses to stress in primates. Proc Natl Acad Sci U S A 97:6079-6084.

Haggerty JJ Jr, Prange AJ Jr (1995): Borderline hypothyroidism and depression. Annu Rev Med 46:37-46.

Hampson RE, Rogers G, Lynch G, Deadwyler SA (1998): Facilitative effects of the ampakine CX516 on short-term memory in rats: enhancement of delayed-nonmatch-to-sample performance. J Neurosci 18:2740-2747.

Hashimoto R, Hough C, Nakazawa T, Yamamoto T, Chuang DM (2002): Lithium protection against glutamate excitotoxicity in rat cerebral cortical neurons: Involvement of NMDA receptor inhibition possibly by decreasing NR2B tyrosine phosphorylation. J Neurochem 80:589-597.

Hayashi T, Umemori H, Mishina M, Yamamoto T (1999): The AMPA receptor interacts with and signals through the protein tyrosine kinase Lyn. Nature 397:72-76.

Haydon PG (2001): GLIA: Listening and talking to the synapse. Nat Rev Neurosci 2:185-193.

Hebenstreit GF, Fellerer K, Fichte K, Fischer G, Geyer N, Meya $\mathrm{U}$, et al (1989): Rolipram in major depressive disorder: Results of a double-blind comparative study with imipramine. Pharmacopsychiatry 22:156-160.

Heninger GR, Charney DS, Sternberg DE (1983): Lithium carbonate augmentation of antidepressant treatment. An effective prescription for treatment-refractory depression. Arch Gen Psychiatry 40:1335-1342.

Heresco-Levy U, Javitt DC (1998): The role of N-methyl-Daspartate (NMDA) receptor-mediated neurotransmission in the pathophysiology and therapeutics of psychiatric syndromes. Eur Neuropsychopharmacol 8:141-152.

Hokin LE, Dixon JF, Los GV (2000): Acute inhibition but chronic upregulation and stabilization of glutamate uptake in synaptosomes by lithium. In Manji HK, Bowden CL and Belmaker RH, editors, Bipolar Medications: mechanisms of action. Washington DC: American Psychiatric Press, 65-85.

Holemans S, De Paermentier F, Horton RW, Crompton MR, Katona CL, Maloteaux JM (1993): NMDA glutamatergic receptors, labelled with [3H] MK-801, in brain samples from drug-free depressed suicides. Brain Res 616:138-143.

Holm KH, Cicchetti F, Bjorklund L, Boonman Z, Tandon P, Costantini LC, et al (2001): Enhanced axonal growth from fetal human bcl-2 transgenic mouse dopamine neurons transplanted to the adult rat striatum. Neuroscience 104:397-405.

Holsboer F (2000): The corticosteroid receptor hypothesis of depression. Neuropsychopharmacology 23:477-501.

Horowski R, Sastre-Y-Hernandez M (1985): Clinical effects of the neurotropic selective cAMP phosphodiesterase inhibitor rolipram in depressed patients: Global evaluation of the preliminary reports. Curr Ther Res 38:23-29.

Huang X, Wu DY, Chen G, Manji H, Chen DF (2003): Support of retinal ganglion cell survival and axon regeneration by lithium through a Bcl-2-dependent mechanism. Invest Ophthalmol Vis Sci 44:347-354.

Huang Z, Ducharme Y, Macdonald D, Robichaud A (2001): The next generation of PDE4 inhibitors. Curr Opin Chem Biol 5:432-438.

Ingvar M, Ambros-Ingerson J, Davis M, Granger R, Kessler M, Rogers GA, et al (1997): Enhancement by an ampakine of memory encoding in humans. Exp Neurol 146:553-554.

Jacobs BL, Praag H, Gage FH (2000): Adult brain neurogenesis and psychiatry: A novel theory of depression. Mol Psychiatry 5:262-269.

Joffe RT (1997): Refractory depression: Treatment strategies, with particular reference to the thyroid axis. J Psychiatry Neurosci 22:327-331.

Jope RS (1999): Anti-bipolar therapy: Mechanism of action of lithium. Mol Psychiatry 4:117-128.

Kalaria RN, Prince AK (1986): Decreased neurotransmitter receptor binding in striatum and cortex from adult hypothyroid rats. Brain Res 364:268-274. 
Karkanias NB, Papke RL (1999): Subtype-specific effects of lithium on glutamate receptor function. $J$ Neurophysiol $81: 1506-1512$.

Kempermann G (2002): Regulation of adult hippocampal neurogenesis-implications for novel theories of major depression. Bipolar Disord 4:17-33.

Kempermann G, Kuhn HG, Gage FH (1997): More hippocampal neurons in adult mice living in an enriched environment. Nature 386:493-495.

Klein PS, Melton DA (1996): A molecular mechanism for the effect of lithium on development. Proc Natl Acad Sci U S A 93:8455-8459.

Korte SM, De Kloet ER, Buwalda B, Bouman SD, Bohus B (1996): Antisense to the glucocorticoid receptor in hippocampal dentate gyrus reduces immobility in forced swim test. Eur J Pharmacol 301:19-25.

Krystal JH, Sanacora G, Blumberg H, Anand A, Charney DS, Marek G, et al (2002): Glutamate and GABA systems as targets for novel antidepressant and mood-stabilizing treatments. Mol Psychiatry 7(suppl 1):S71-S80.

Lauterborn JC, Lynch G, Vanderklish P, Arai A, Gall CM (2000): Positive modulation of AMPA receptors increases neurotrophin expression by hippocampal and cortical neurons. J Neurosci 20:8-21.

Legutko B, Li X, Skolnick P (2001): Regulation of BDNF expression in primary neuron culture by LY392098, a novel AMPA receptor potentiator. Neuropharmacology 40:10191027.

Lenox RH, Gould TD, Manji HK (2002): Endophenotypes in bipolar disorder. Am J Med Genet 114:391-406.

Levine J, Panchalingam K, Rapoport A, Gershon S, McClure RJ, Pettegrew JW (2000): Increased cerebrospinal fluid glutamine levels in depressed patients. Biol Psychiatry 47:586593.

Li X, Bijur GN, Jope RS (2002): Glycogen synthase kinase3beta, mood stabilizers, and neuroprotection. Bipolar Disord $4: 137-144$.

Li X, Tizzano JP, Griffey K, Clay M, Lindstrom T, Skolnick P (2001): Antidepressant-like actions of an AMPA receptor potentiator (LY392098). Neuropharmacology 40:1028-1033.

Lopez JF, Chalmers DT, Little KY, Watson SJ (1998): A.E. Bennett Research Award. Regulation of serotonin1A, glucocorticoid, and mineralocorticoid receptor in rat and human hippocampus: Implications for the neurobiology of depression. Biol Psychiatry 43:547-573.

Lu EJ, Brown WJ (1977a): The developing caudate nucleus in the euthyroid and hypothyroid rat. J Comp Neurol 171:261284.

Lu EJ, Brown WJ (1977b): An electron microscopic study of the developing caudate nucleus in euthyroid and hypothyroid states. Anat Embryol (Berl) 150:335-364.

Lynch G, Granger R, Ambros-Ingerson J, Davis CM, Kessler M, Schehr R (1997): Evidence that a positive modulator of AMPA-type glutamate receptors improves delayed recall in aged humans. Exp Neurol 145:89-92.

Lyons DM (2002): Stress, depression, and inherited variation in primate hippocampal and prefrontal brain development. Psychopharmacol Bull 36:27-43.
Lyons DM, Yang C, Sawyer-Glover AM, Moseley ME, Schatzberg AF (2001): Early life stress and inherited variation in monkey hippocampal volumes. Arch Gen Psychiatry 58:1145-1151.

Maes M, Verkerk R, Vandoolaeghe E, Lin A, Scharpe S (1998): Serum levels of excitatory amino acids, serine, glycine, histidine, threonine, taurine, alanine and arginine in treatment-resistant depression: Modulation by treatment with antidepressants and prediction of clinical responsivity. Acta Psychiatr Scand 97:302-308.

Mamounas LA, Blue ME, Siuciak JA, Altar CA (1995): Brainderived neurotrophic factor promotes the survival and sprouting of serotonergic axons in rat brain. J Neurosci 15:79297939.

Manev H, Uz T, Smalheiser NR, Manev R (2001): Antidepressants alter cell proliferation in the adult brain in vivo and in neural cultures in vitro. Eur J Pharmacol 411:67-70.

Manji H, Du J, Gould T (in press): The role of neurotrophic signaling pathways in mood disorders. In: Gutkind J, editor. Signal Transduction and Human Disease.

Manji H, Duman R (2001): Impairments of neuroplasticity and cellular resilience in severe mood disorder: Implications for the development of novel therapeutics. Psychopharmacol Bull 35:5-49.

Manji HK, Drevets WC, Charney DS (2001a): The cellular neurobiology of depression. Nat Med 7:541-547.

Manji HK, Lenox RH (2000): Signaling: Cellular insights into the pathophysiology of bipolar disorder. Biol Psychiatry 48:518-530.

Manji HK, Moore GJ, Chen G (2001b): Bipolar disorder: Leads from the molecular and cellular mechanisms of action of mood stabilizers. Br J Psychiatry 178(suppl 41):S107-S119.

Manji HK, Moore GJ, Rajkowska G, Chen G (2000): Neuroplasticity and cellular resilience in mood disorders. Mol Psychiatry 5:578-593.

Mathis P, Schmitt L, Benatia M, Granier F, Ghisolfi J, Moron P (1988): Perturbations des acides amines plasmatiques et depression (Plasma amino acid disturbances and depression). Encephale 14:77-82.

Matsumoto T, Numakawa T, Adachi N, Yokomaku D, Yamagishi S, Takei N, et al (2001): Brain-derived neurotrophic factor enhances depolarization-evoked glutamate release in cultured cortical neurons. J Neurochem 79:522-530.

Mauri MC, Ferrara A, Boscati L, Bravin S, Zamberlan F, Alecci M, et al (1998): Plasma and platelet amino acid concentrations in patients affected by major depression and under fluvoxamine treatment. Neuropsychobiology 37:124-129.

McEwen BS (1999): Stress and hippocampal plasticity. Annu Rev Neurosci 22:105-122.

McQuade R, Young AH (2000): Future therapeutic targets in mood disorders: The glucocorticoid receptor. Br J Psychiatry 177:390-395.

Meador-Woodruff JH, Hogg AJ Jr, Smith RE (2001): Striatal ionotropic glutamate receptor expression in schizophrenia, bipolar disorder, and major depressive disorder. Brain Res Bull 55:631-640.

Mesulam MM (1999): Neuroplasticity failure in Alzheimer's disease: Bridging the gap between plaques and tangles. Neuron 24:521-529. 
Michael-Titus AT, Bains S, Jeetle J, Whelpton R (2000): Imipramine and phenelzine decrease glutamate overflow in the prefrontal cortex-a possible mechanism of neuroprotection in major depression? Neuroscience 100:681-4.

Miguel-Hidalgo JJ, Rajkowska G (2002): Morphological brain changes in depression: can antidepressants reverse them? CNS Drugs 16:361-372.

Moore GJ, Bebchuk JM, Hasanat K, Chen G, Seraji-Bozorgzad $\mathrm{N}$, Wilds IB, et al (2000a): Lithium increases N-acetylaspartate in the human brain: In vivo evidence in support of bcl-2's neurotrophic effects? Biol Psychiatry 48:1-8.

Moore GJ, Bebchuk JM, Wilds IB, Chen G, Manji HK (2000b): Lithium-induced increase in human brain grey matter. Lancet 356:1241-1242.

Moore GJ, Galloway MP (2002): Magnetic resonance spectroscopy: neurochemistry and treatment effects in affective disorders. Psychopharmacol Bull 36:5-23.

Murray CJ, Lopez AD (1997): Global mortality, disability, and the contribution of risk factors: Global Burden of Disease Study. Lancet 349:1436-1442.

Musselman DL, Evans DL, Nemeroff CB (1998): The relationship of depression to cardiovascular disease: Epidemiology, biology, and treatment. Arch Gen Psychiatry 55:580-592.

Nakamura S (1990): Antidepressants induce regeneration of catecholaminergic axon terminals in the rat cerebral cortex. Neurosci Lett 111:64-68.

Nestler EJ, Barrot M, DiLeone RJ, Eisch AJ, Gold SJ, Monteggia LM (2002): Neurobiology of depression. Neuron 34:13-25.

Nibuya M, Morinobu S, Duman RS (1995): Regulation of BDNF and trkB mRNA in rat brain by chronic electroconvulsive seizure and antidepressant drug treatments. J Neurosci 15:7539-7547.

Nibuya M, Nestler EJ, Duman RS (1996): Chronic antidepressant administration increases the expression of cAMP response element binding protein (CREB) in rat hippocampus. J Neurosci 16:2365-2372.

Nibuya M, Takahashi M, Russell DS, Duman RS (1999): Repeated stress increases catalytic TrkB mRNA in rat hippocampus. Neurosci Lett 267:81-84.

Nonaka S, Chuang DM (1998): Neuroprotective effects of chronic lithium on focal cerebral ischemia in rats. Neuroreport 9:2081-2084.

Nonaka S, Hough CJ, Chuang DM (1998): Chronic lithium treatment robustly protects neurons in the central nervous system against excitotoxicity by inhibiting N-methyl-D-aspartate receptor-mediated calcium influx. Proc Natl Acad Sci U S A 95:2642-2647.

Nowak G, Li Y, Paul IA (1996): Adaptation of cortical but not hippocampal NMDA receptors after chronic citalopram treatment. Eur J Pharmacol 295:75-85.

Nowak G, Ordway GA, Paul IA (1995a): Alterations in the $\mathrm{N}$-methyl-D-aspartate (NMDA) receptor complex in the frontal cortex of suicide victims. Brain Res 675:157-164.

Nowak G, Paul IA, Popik P, Young A, Skolnick P (1993): Ca2+ antagonists effect an antidepressant-like adaptation of the NMDA receptor complex. Eur J Pharmacol 247:101-102.

Nowak G, Redmond A, McNamara M, Paul IA (1995b): Swim stress increases the potency of glycine at the N-methyl-Daspartate receptor complex. J Neurochem 64:925-927.
Ochs G, Penn RD, York M, Giess R, Beck M, Tonn J, et al (2000): A phase I/II trial of recombinant methionyl human brain derived neurotrophic factor administered by intrathecal infusion to patients with amyotrophic lateral sclerosis. Amyotroph Lateral Scler Other Motor Neuron Disord 1:201206.

O'Donnell JM (1993): Antidepressant-like effects of rolipram and other inhibitors of cyclic adenosine monophosphate phosphodiesterase on behavior maintained by differential reinforcement of low response rate. J Pharmacol Exp Ther 264:1168-1178

Oh YJ, Swarzenski BC, O’Malley KL (1996): Overexpression of $\mathrm{Bcl}-2$ in a murine dopaminergic neuronal cell line leads to neurite outgrowth. Neurosci Lett 202:161-164.

Ongur D, Drevets WC, Price JL (1998): Glial reduction in the subgenual prefrontal cortex in mood disorders. Proc Natl Acad Sci U S A 95:13290-13295.

Orford M, Mazurkiewicz D, Milligan G, Saggerson D (1991): Abundance of the alpha-subunits of Gi1, Gi2 and Go in synaptosomal membranes from several regions of the rat brain is increased in hypothyroidism. Biochem $J 275(\mathrm{Pt}$ 1):183-186.

Orford MR, Leung FC, Milligan G, Saggerson ED (1992): Treatment with triiodothyronine decreases the abundance of the alpha-subunits of Gi1 and Gi2 in the cerebral cortex. J Neurol Sci 112:34-37.

Owens MJ, Nemeroff CB (1999): Corticotropin-releasing factor antagonists in affective disorders. Expert Opin Investig Drugs 8:1849-1858.

Parkes JD, Calver DM, Zilkha KJ, Knill-Jones RP (1970): Controlled trial of amantadine hydrochloride in Parkinson's disease. Lancet 1:259-262.

Patapoutian A, Reichardt LF (2001): Trk receptors: Mediators of neurotrophin action. Curr Opin Neurobiol 11:272-280.

Patel PD, Lopez JF, Lyons DM, Burke S, Wallace M, Schatzberg AF (2000): Glucocorticoid and mineralocorticoid receptor mRNA expression in squirrel monkey brain. J Psychiatr Res 34:383-392.

Paul IA, Trullas R, Skolnick P, Nowak G (1992): Downregulation of cortical beta-adrenoceptors by chronic treatment with functional NMDA antagonists. Psychopharmacology (Berl) 106:285-287.

Payne J, Quiroz J, Gould T, Zarate C, Manji H (in press): The cellular neurobiology of bipolar disorder. In Charney DS, Nestler EJ (eds), Neurobiology of Mental Illness. New York: Oxford University Press.

Payne JL, Quiroz JA, Zarate CA, Manji HK (2002): Timing is everything: Does the robust upregulation of noradrenergically regulated plasticity genes underlie the rapid antidepressant effects of sleep deprivation? Biol Psychiatry 52:921-926.

Pettmann B, Henderson CE (1998): Neuronal cell death. Neuron 20:633-647.

Phiel CJ, Klein PS (2001): Molecular targets of lithium action. Annu Rev Pharmacol Toxicol 41:789-813.

Pillay SS, Yurgelun-Todd DA, Bonello CM, Lafer B, Fava M, Renshaw PF (1997): A quantitative magnetic resonance imaging study of cerebral and cerebellar gray matter volume in primary unipolar major depression: Relationship to treat- 
ment response and clinical severity. Biol Psychiatry 42:7984.

Poo MM (2001): Neurotrophins as synaptic modulators. Nat Rev Neurosci 2:24-32.

Prange AJ Jr (1996): Novel uses of thyroid hormones in patients with affective disorders. Thyroid 6:537-543.

Quiroz JA, Manji HK (2002): Enhancing synaptic plasticity and cellular resilience to develop novel, improved treatments for mood disorders. Dialogues Clin Neurosci 4:73-92.

Rajkowska G (2000a): Histopathology of the prefrontal cortex in major depression: What does it tell us about dysfunctional monoaminergic circuits? Prog Brain Res 126:397-412.

Rajkowska G (2000b): Postmortem studies in mood disorders indicate altered numbers of neurons and glial cells. Biol Psychiatry 48:766-777.

Rajkowska G (2002): Cell pathology in bipolar disorder. Bipolar Disord 4:105-116.

Rajkowska G, Miguel-Hidalgo JJ, Wei J, Dilley G, Pittman SD, Meltzer HY, et al (1999): Morphometric evidence for neuronal and glial prefrontal cell pathology in major depression. Biol Psychiatry 45:1085-1098.

Reul JM, Holsboer F (2002): Corticotropin-releasing factor receptors 1 and 2 in anxiety and depression. Curr Opin Pharmacol 2:23-33.

Reus VI, Wolkowitz OM (2001): Antiglucocorticoid drugs in the treatment of depression. Expert Opin Investig Drugs 10:1789-1796.

Reynolds IJ, Miller RJ (1988): Tricyclic antidepressants block N-methyl-D-aspartate receptors: Similarities to the action of zinc. Br J Pharmacol 95:95-102.

Riccio A, Ahn S, Davenport CM, Blendy JA, Ginty DD (1999): Mediation by a CREB family transcription factor of NGFdependent survival of sympathetic neurons. Science 286:2358-2361.

Ruiz-Marcos A, Cartagena-Abella P, Martinez-Galan JR, Calvo R, Morreale de Escobar G, Escobar del Rey F (1994): Thyroxine treatment and the recovery of pyramidal cells of the cerebral cortex from changes induced by juvenile-onset hypothyroidism. J Neurobiol 25:808-818.

Ruiz-Marcos A, Sanchez-Toscano F, Escobar del Rey F, Morreale de Escobar G (1979): Severe hypothyroidism and the maturation of the rat cerebral cortex. Brain Res 162:315-329.

Ruiz-Marcos A, Sanchez-Toscano F, Escobar del Rey F, Morreale de Escobar G (1980): Reversible morphological alterations of cortical neurons in juvenile and adult hypothyroidism in the rat. Brain Res 185:91-102.

Sanchez MM, Young LJ, Plotsky PM, Insel TR (2000): Distribution of corticosteroid receptors in the rhesus brain: Relative absence of glucocorticoid receptors in the hippocampal formation. J Neurosci 20:4657-4668.

Sapolsky RM (1996): Stress, glucocorticoids, and damage to the nervous system: The current state of confusion. Stress 1:1-19.

Sapolsky RM (2000): Glucocorticoids and hippocampal atrophy in neuropsychiatric disorders. Arch Gen Psychiatry 57:925935.

Schinder AF, Berninger B, Poo M (2000): Postsynaptic target specificity of neurotrophin-induced presynaptic potentiation. Neuron 25:151-163.
Scott AI, Perini AF, Shering PA, Whalley LJ (1991): In-patient major depression: Is rolipram as effective as amitriptyline? Eur J Clin Pharmacol 40:127-129.

Simmons NE, Alden TD, Thorner MO, Laws ER Jr (2001): Serum cortisol response to transsphenoidal surgery for Cushing disease. J Neurosurg 95:1-8.

Skolnick P (1999): Antidepressants for the new millennium. Eur J Pharmacol 375:31-40.

Skolnick P, Layer RT, Popik P, Nowak G, Paul IA, Trullas R (1996): Adaptation of N-methyl-D-aspartate (NMDA) receptors following antidepressant treatment: Implications for the pharmacotherapy of depression. Pharmacopsychiatry 29:2326.

Skolnick P, Legutko B, Li X, Bymaster FP (2001): Current perspectives on the development of non-biogenic aminebased antidepressants. Pharmacol Res 43:411-423.

Smith MA, Makino S, Kvetnansky R, Post RM (1995): Stress and glucocorticoids affect the expression of brain-derived neurotrophic factor and neurotrophin-3 mRNAs in the hippocampus. J Neurosci 15:1768-1777.

Sporn J, Ghaemi SN, Sambur MR, Rankin MA, Recht J, Sachs GS, et al (2000): Pramipexole augmentation in the treatment of unipolar and bipolar depression: A retrospective chart review. Ann Clin Psychiatry 12:137-140.

Starkman MN, Giordani B, Gebarski SS, Berent S, Schork MA, Schteingart DE (1999): Decrease in cortisol reverses human hippocampal atrophy following treatment of Cushing's disease. Biol Psychiatry 46:1595-1602.

Steffens DC, Helms MJ, Krishnan KR, Burke GL (1999): Cerebrovascular disease and depression symptoms in the cardiovascular health study. Stroke 30:2159-2166.

Steffens DC, Krishnan KR (1998): Structural neuroimaging and mood disorders: Recent findings, implications for classification, and future directions. Biol Psychiatry 43:705-712.

Stoll AL, Renshaw PF, Yurgelun-Todd DA, Cohen BM (2000): Neuroimaging in bipolar disorder: What have we learned? Biol Psychiatry 48:505-517.

Takahashi M, Terwilliger R, Lane C, Mezes PS, Conti M, Duman RS (1999): Chronic antidepressant administration increases the expression of cAMP-specific phosphodiesterase 4A and 4B isoforms. J Neurosci 19:610-618.

Takata K, Kitamura Y, Kakimura J, Kohno Y, Taniguchi T (2000): Increase of bcl-2 protein in neuronal dendritic processes of cerebral cortex and hippocampus by the antiparkinsonian drugs, talipexole and pramipexole. Brain Res 872:236-241.

Taylor WD, Payne ME, Krishnan KR, Wagner HR, Provenzale JM, Steffens DC, MacFall JR (2001): Evidence of white matter tract disruption in MRI hyperintensities. Biol Psychiatry 50:179-183.

Thoenen H (1995): Neurotrophins and neuronal plasticity. Science 270:593-598.

Thomas AJ, Ferrier IN, Kalaria RN, Davis S, O'Brien JT (2002): Cell adhesion molecule expression in the dorsolateral prefrontal cortex and anterior cingulate cortex in major depression in the elderly. Br J Psychiatry 181:129-134.

Thomas AJ, Ferrier IN, Kalaria RN, Woodward SA, Ballard C, Oakley A, et al (2000): Elevation in late-life depression of 
intercellular adhesion molecule-1 expression in the dorsolateral prefrontal cortex. Am J Psychiatry 157:1682-1684.

Thome J, Sakai N, Shin K, Steffen C, Zhang YJ, Impey S, et al (2000): CAMP response element-mediated gene transcription is upregulated by chronic antidepressant treatment. J Neurosci 20:4030-4036.

Trullas R, Skolnick P (1990): Functional antagonists at the NMDA receptor complex exhibit antidepressant actions. Eur J Pharmacol 185:1-10.

Tsai G, Coyle JT (1995): N-acetylaspartate in neuropsychiatric disorders. Prog Neurobiol 46:531-540.

Ullian EM, Sapperstein SK, Christopherson KS, Barres BA (2001): Control of synapse number by glia. Science 291:657661.

Vale S, Espejel MA, Dominguez JC (1971): Amantadine in depression. Lancet 2:437.

van Praag H, Kempermann G, Gage FH (1999): Running increases cell proliferation and neurogenesis in the adult mouse dentate gyrus. Nat Neurosci 2:266-270.

Vincent S, Todtenkopf M, Benes F (1997): A comparison of the density of pyramidal and nonpyramydal neurons in the anterior cingulate cortex in schizophrenics and manic depressives. Society for Neuroscience 23:2199.

Wachtel H, Schneider HH (1986): Rolipram, a novel antidepressant drug, reverses the hypothermia and hypokinesia of monoamine-depleted mice by an action beyond postsynaptic monoamine receptors. Neuropharmacology 25:1119-1126.

Watanabe Y, Gould E, Daniels DC, Cameron H, McEwen BS (1992): Tianeptine attenuates stress-induced morphological changes in the hippocampus. Eur J Pharmacol 222:157-162.
Wei H, Qin ZH, Senatorov VV, Wei W, Wang Y, Qian Y, et al (2001): Lithium suppresses excitotoxicity-induced striatal lesions in a rat model of Huntington's disease. Neuroscience 106:603-612.

Wellman CL (2001): Dendritic reorganization in pyramidal neurons in medial prefrontal cortex after chronic corticosterone administration. $J$ Neurobiol 49:245-253.

Young LT (2001): Postreceptor pathways for signal transduction in depression and bipolar disorder. J Psychiatry Neurosci 26(suppl):S17-S22.

Young LT (2002): Neuroprotective effects of antidepressant and mood stabilizing drugs. J Psychiatry Neurosci 27:8-9.

Yuan PX, Huang LD, Jiang YM, Gutkind JS, Manji HK, Chen G (2001): The mood stabilizer valproic acid activates mitogenactivated protein kinases and promotes neurite growth. J Biol Chem 276:31674-1683.

Zarate C, Quiroz J, Payne J, Manji H (2003): Modulators of the glutamatergic system: Implications for the development of improved therapeutics in mood disorders. Psychopharmacol Bull 36:35-83.

Zeller E, Stief HJ, Pflug B, Sastre-Y-Hernandez M (1984): Results of a phase II study of the antidepressant effect of rolipram. Pharmacopsychiatry 17:188-190.

Zobel AW, Nickel T, Kunzel HE, Ackl N, Sonntag A, Ising M, et al (2000): Effects of the high-affinity corticotropin-releasing hormone receptor 1 antagonist R121919 in major depression: The first 20 patients treated. J Psychiatr Res 34:171181. 


\section{Appendix 1. Brain Imaging Studies Demonstrating Atrophic Volumetric Changes in Mood Disorders ${ }^{a}$}

\begin{tabular}{|c|c|c|c|}
\hline CT Studies & Subjects & Measurement & Major Finding \\
\hline Andreasen et al 1990 & $\begin{array}{l}24 \text { BD patients, } 27 \mathrm{UP} \\
\text { depressed patients, } 108 \mathrm{SZ} \\
\text { patients and } 75 \mathrm{CS}\end{array}$ & VBR & $\begin{array}{l}\text { Male BD patients had increased VBR. } \\
\text { Depressed patients showed no significant } \\
\text { difference }\end{array}$ \\
\hline Baumann et al 1997 & $\begin{array}{l}23 \text { patients with exogenous } \\
\text { depression, } 28 \text { patients with } \\
\text { neurotic depression and } 56 \\
\text { CS }\end{array}$ & $\begin{array}{l}\text { VBR, third ventricle, frontal } \\
\text { sulci, parieto-occipital sulci, } \\
\text { interhemispheric fissure, } \\
\text { sylvian fissure }\end{array}$ & $\begin{array}{l}\text { Female patients with exogenous depression } \\
\text { exhibited widened bilateral upper cortical } \\
\text { sulci and third ventricular enlargement }\end{array}$ \\
\hline Beats et al 1991 & $\begin{array}{l}25 \text { elderly MD (4 BD) patients } \\
\text { and } 25 \mathrm{CS}\end{array}$ & Ventricle size, hyperintensities & $\begin{array}{l}\text { Larger third ventricule associated with } \\
\text { greater number of episodes, age and } \\
\text { duration of the illness }\end{array}$ \\
\hline Dewan et al 1988 & 26 patients with $\mathrm{BD}, 22 \mathrm{CS}$ & $\begin{array}{l}\text { Ventricle size, cortical } \\
\text { atrophy, brain density }\end{array}$ & BD had increased third ventricle width \\
\hline Dolan et al 1986 & $\begin{array}{l}101 \text { patients with UP } \\
\text { depression, } 52 \text { CS }\end{array}$ & VBR, cortical atrophy & $\begin{array}{l}\text { Depressed patients showed increased sulcal } \\
\text { widening and lateral ventricle size }\end{array}$ \\
\hline Johnstone et al 1986 & $\begin{array}{l}19 \text { neurotic patients, } 22 \mathrm{BD} \\
\text { outpatients, and } 10 \mathrm{BD} \\
\text { inpatients }\end{array}$ & VBR, lateral ventricular size & $\begin{array}{l}19 \% \text { of BD patients had VBR more than } \\
\text { two standard deviations above the } \\
\text { neurotic mean }\end{array}$ \\
\hline Nasrallah et al 1982 & $\begin{array}{l}55 \text { patients with SZ, } 24 \\
\text { patients with mania, and } 27 \\
\text { CS }\end{array}$ & VBR & $\begin{array}{l}\text { Both SZ and manic patients had greater } \\
\text { VBRs than CS; no differences between } \\
\text { patient groups }\end{array}$ \\
\hline Pearlson and Veroff 1981 & $\begin{array}{l}16 \text { patients with affective } \\
\text { disorder, } 22 \text { with SZ, } 35 \text { CS }\end{array}$ & VBR, cortical atrophy & $\begin{array}{l}\text { Both SZ and affective disorder patients } \\
\text { showed increased VBR }\end{array}$ \\
\hline Pearlson et al 1984 & $27 \mathrm{BD}$ patients and $27 \mathrm{CS}$ & VBR & $\begin{array}{l}\text { BD had larger VBR than CS, associated } \\
\text { with frequent hospitalizations }\end{array}$ \\
\hline Pearlson et al 1989 & $\begin{array}{l}26 \text { elderly patients with } \\
\text { depression (including } 15 \\
\text { cognitively impaired), } 13 \\
\text { patients with Alzheimer's }\end{array}$ & VBR, brain density & $\begin{array}{l}\text { Depressed patients with cognitive } \\
\text { impairment (not depression alone) } \\
\text { showed increased VBR and decreased } \\
\text { brain density }\end{array}$ \\
\hline
\end{tabular}

Schlegel and Kretzschmar $1987 \quad 60$ patients with affective

disorder (33 UP, 22 BD [17

Ventricle size, cortical atrophy

Frontal horns, bicaudate distance and third ventricle were enlarged in affective disorder patients

Shima et al 1984

46 depressed (2 BD) patients and $46 \mathrm{CS}$

Shiraishi et al 1992

45 nondelusional and 29 delusional MD patients, 77 CS

Swayze et al 1990

48 patients with $\mathrm{BD}, 54 \mathrm{SZ}$ patients, and $47 \mathrm{CS}$

VBR

Patients had increased VBR

Cerebral atrophy ratio (CAR) and VBR

Nondelusional depressed patients had higher CAR than controls. Delusional depressed patients had greater VBR and CAR than nondelusional and CS

Lateral ventricular volumes, hyperintensities

$\mathrm{BD}$ had trends toward enlarged lateral ventricles; BP patients with focal hyperintensities showed trends for larger lateral ventricles size compared to those without focal hyperintensities

Tanaka et al 1982

$40 \mathrm{BD}$ patients, $40 \mathrm{CS}$

\section{Ventricle size, cortical atrophy, asymmetry}

Weinberger et al 1982

Wurthmann et al 1995

Ventricular size and vermis

Frontal and parieto-occipital
23 patients with affective disorder, 35 first schizophreniform episode, 17 chronic SZ patients, 27 other psychiatric diagnoses patients, $26 \mathrm{CS}$

34 patients with MD, 29 patients with degenerative dementia, 43 CS

Compared with CS, patients $\geq 50$ years old showed cortical atrophy, and patients had reversed cerebral asymmetry

Affective patients had vermian atrophy vs. other diagnostic groups and CS sulci, Sylvian fissures, lateral and third ventricles

Remarkable enlargement of left Sylvian fissure and more subtle enlargements of ventricles, cortical sulci, and right Sylvian fissure was found in the depressed group vs. CS. The demented patients showed a more generalized brain atrophy.

Patients had greater cortical sulcal widening scores compared with CS 


\section{Appendix 1. Continued}

\begin{tabular}{|c|c|}
\hline MRI Studies & Subjects \\
\hline Ali et al 2001 & $26 \mathrm{BD}$ patients \\
\hline Altshuler et al 1991 & $10 \mathrm{BD}$ I patients and $10 \mathrm{CS}$ \\
\hline Ashtari et al 1999 & $\begin{array}{l}40 \text { UP depressive geriatric } \\
\text { patients and } 46 \text { CS }\end{array}$ \\
\hline Bakshi et al 2000 & $\begin{array}{l}\text { All multiple sclerosis patients: } \\
19 \text { DP, } 29 \text { non DP }\end{array}$ \\
\hline Botteron et al 2002 & $\begin{array}{l}30 \text { young women with early } \\
\text { onset MD, } 18 \text { middle aged } \\
\text { women with recurrent MD, } \\
17 \mathrm{CS}\end{array}$ \\
\hline Brambilla et al 2001a & $22 \mathrm{BD}$ patients and $22 \mathrm{CS}$ \\
\hline
\end{tabular}

Brambilla et al 2001b $22 \mathrm{BD}$ patients and $22 \mathrm{CS}$

Bremner et al 2000

Bremner et al 2002

Coffey et al 1993

Coffman et al 1990

Dahabra et al 1998

Dasari et al 1999

DelBello et al 1999

Drevets et al 1997

Friedman et al 1999 remission 16 matched $\mathrm{CS}$

15 patients with MD in remission and $20 \mathrm{CS}$

48 patients with affective disorder (44 UP, 4 BD) and $76 \mathrm{CS}$

$30 \mathrm{BD}$ patients and $52 \mathrm{CS}$

23 elderly patients, recovered from MD (12 late onset and 22 early onset of depression) and $15 \mathrm{CS}$

Adolescents: 15 BD patients, $20 \mathrm{SZ}$ patients and 16 normal CS

16 first-episode BD patients, 14 multiple-episode BD patients and $15 \mathrm{CS}$

21 patients with $\mathrm{BD}, 21$ patients with MDD, and 21 healthy CS

20 adolescent SZ patients, 16 adolescent BD patients, and 16 adolescent CS
16 patients with $\mathrm{MD}$ in
Subgenual prefrontal cortex (SGPFC)

Caudate and putamen gray matter volumes, globus pallidus total volume

Temporal lobes, hippocampi third ventricule, areas of lateral ventricules

Temporal lobe volume

Hippocampus volume, anterior hippocampus / amygdala complex

Cortical atrophy, ventricle size, hyperintensities

Fosa posterior: cerebellum, vermis, brainstem. Brain ventricules

HIP, amygdala, caudate, frontal lobe, temporal lobe, whole brain volumes

Orbitofrontal cortex and other frontal cortical regions

Cerebral volume, cortical atrophy, ventricle size, hyperintensities

Midsagittal areas, frontal area and cognitive tasks

Ventricles size, subcortical white matter lesions

Thalamic area

Cerebellum

Cortex volume of subcallosal anterior cingulate gyrus (subgenual prefrontal cortex)

Intracranial volume and ventricular and sulcal enlargement

\section{Major Finding}

Larger third ventricule associated with greater number of episodes

Smaller temporal lobe volume in BD patients, bilaterally

No differences between UP patients and $\mathrm{CS}$; in patients, reduced HIP volumes correlated with age and depression ratings

Severity of depression was predicted by superior frontal, superior parietal and temporal TI lesions, lateral and third ventricular enlargement, and frontal atrophy

Patients had reduced left SGPFC

No differences between BD patients and CS. Age inversely correlated with left putamen volume in patients. Length of illness predicted smaller left putamen volumes

No differences between BD patients and CS. Age correlated with third ventricule volume in patients. Number of prior episodes correlated with right lateral ventricule volumes. Familial patients had smaller cerebellar hemispheres and total vermis volumes, and larger left ventricules vs. nonfamilial patients

Patients with depression had a 19\% smaller left HIP volume

Patients had $32 \%$ smaller medial orbitofrontal (gyrus rectus) cortical volume than CS

Affective disorder patients showed decreased frontal lobe volume

Patients had smaller mean area for the corpus callosum and tended to have smaller mean frontal area

Patients with late onset depression had larger third and lateral ventricles, and increased VBR than early onset patients

Reduced thalamic area in patients vs. CS. No difference between patients groups

V3 area was significantly smaller in multiple-episode patients compared with either first-episode patients or CS

Reduced volume on left in both BD patients and MDD patients relative to healthy CS.

In the combined SZ/BD group, reduced intracranial volume and increased frontal and temporal sulcal size observed 


\section{Appendix 1. Continued}

\begin{tabular}{lc}
\hline MRI Studies & Subjects \\
\hline Frodl et al 2002a & $\begin{array}{c}30 \text { patients, first MD episode } \\
\text { and 30 CS }\end{array}$ \\
Frodl et al 2002b & $\begin{array}{c}30 \text { patients, first MD episode } \\
\text { and 30 CS }\end{array}$ \\
Hauser et al 1989 & $\begin{array}{c}17 \text { patients with primary } \\
\text { affective disorder and 21 CS }\end{array}$ \\
Hauser et al 2000 & 25 BPI, 22 BPII patients and \\
19 CS
\end{tabular}

Hirayasu et al 1999

Husain et al 1991

Kato et al 1994

Krishnan et al 1992

Kumar et al 1997

Kumar et al 1998

Kumar et al 2000

Lai et al 2000

Lim et al 1999

Mervaala et al 2000

Noga et al 2001

Pantel et al 1997

Parashos et al 1998
24 patients experiencing their first episode of affective disorder, 17 patients experiencing their first episode of SZ, and $20 \mathrm{CS}$

41 patients with depression, 44 CS

40 patients with BD (31 BPI and 9 BPII), $60 \mathrm{CS}$

50 patients with depression, 50 CS

28 subjects with late-life MDD, $29 \mathrm{CS}$, and 34 subjects with probable DAT

18 patients with late-onset minor depression, 35 patients with late-onset MD and $30 \mathrm{CS}$

51 patients with late-life MDD and 30 non-depressed CS

20 elderly MD patients and 20 CS

9 BD patients, 9 SZ patients, and $16 \mathrm{CS}$

34 drug-resistant MD patients and $17 \mathrm{CS}$

6 pair of $\mathrm{MZ}$ twins discordant for $\mathrm{BD}$, and 11 pair of normal MZ twins

19 patients with late-onset MD, 27 patients with Alzheimer's disease, $13 \mathrm{CS}$ 72 patients with MD, $38 \mathrm{CS}$
Amygdala volume

Hippocampal volume

Ratio of temporal lobe to cerebral area

Temporal lobe, hippocampus and ventricular areas

Subgenual cingulate volume

Putamen volume

Ventricular enlargement

Caudate volume, cerebral volume, bicaudate distance, bifrontal distance

Cerebrospinal fluid volumes, high-intensity signals

Prefrontal brain, temporal brain, whole brain

Absolute and normalized measures of brain and lesion volumes

Orbital frontal cortex

Global cortical gray matter, white matter and sulcal $\mathrm{CSF}$, and lateral and third ventricular volume

Amygdala and hippocampus

Basal ganglia, amygdalahippocampus, and cerebral hemispheres volumes

Whole brain, CSF, frontal and temporal lobes, amygdalahippocampus complex

Whole brain, whole-brain ratio, frontal orbitofrontal, frontal ratio, caudate, putamen, thalamus, cerebellum, corpus callosum, lateral ventricles
Increased amygdala volume in both hemispheres

Male patients had smaller HIP total and gray matter volumes. Male and female patients had reductions in HIP white matter

The ratio of the temporal lobe to the cerebral area was smaller in patients than CS both on the left and right

Lateral ventricle area and lateral ventricle/ cerebrum area ratio were larger in BPI vs. BPII patients or CS in left hemisphere

Smaller left subgenual cingulate volumes in familial affective disorder patients compared to nonfamilial patients or CS SZ patients did not differ from CS.

Smaller putamen volume in depressed patients; age negatively correlated with putamen size in both patients and CS

Patients had larger ventricular size vs. CS

Depressed patients had decreased bilateral caudate volumes

Depressed subjects showed increases in CSF volumes, which were comparable to the DAT group

Normalized prefrontal lobe volumes showed a significant linear (negative) trend with severity of depression

Patients with MDD had significantly smaller frontal lobe volumes

Reduced right and left orbital frontal cortex in patients

BD patients had widespread volume deficits of cortical gray matter but not of cortical white matter compared to CS, but less than SZ patients

Smaller left hippocampus in patients vs. CS; patients had significant asymmetry in amygdalar volume (right smaller than left)

Right hippocampus was smaller in the sick vs. well BD twins. Less HIP asymmetry in the affected vs. unaffected BD twin and the normal $\mathrm{MZ}$ twins

Lower whole brain volume and increased CSF volume and VBR in depressed patients

Lower volumes of the basal ganglia (caudate and putamen) in depressed patients 


\section{Appendix 1. Continued}

\begin{tabular}{|c|c|}
\hline MRI Studies & Subjects \\
\hline Pillay et al 1998 & $\begin{array}{l}38 \text { UP depressed patients and } \\
20 \mathrm{CS}\end{array}$ \\
\hline Rabins et al 1991 & $\begin{array}{l}21 \text { elderly patients with } \\
\text { depression, } 16 \text { with } \\
\text { Alzheimer's disease, } 14 \mathrm{CS}\end{array}$ \\
\hline Rabins et al 2000 & $\begin{array}{l}14 \text { late-life BD patients, } 14 \\
\text { late-life UP MD, } 14 \text { late- } \\
\text { onset SZ, } 21 \mathrm{CS}\end{array}$ \\
\hline Roy et al 1998 & $\begin{array}{l}22 \text { patients with chronic SZ, } \\
14 \text { patients with } \mathrm{BP} \text {, and } 15 \\
\mathrm{CS}\end{array}$ \\
\hline Sassi et al 2001 & $\begin{array}{l}23 \mathrm{BD} \text { patients, } 13 \mathrm{UP} \text { patients } \\
\text { and } 34 \mathrm{CS}\end{array}$ \\
\hline Sax et al 1999 & $\begin{array}{l}17 \text { patients with mania and } 12 \\
\text { CS }\end{array}$ \\
\hline Shah et al 1992 & $\begin{array}{l}27 \text { patients with MD and } 36 \\
\text { CS }\end{array}$ \\
\hline
\end{tabular}

Shah et al 1998

Sheline et al 1996

Sheline et al 1998

Sheline et al 1999

Simpson et al 1999

Simpson et al 2001

Steffens et al 2000

Strakowski et al 1993
20 patients with MD, 20 patients who had recovered from depression and $20 \mathrm{CS}$ CS

20 patients with depression and $20 \mathrm{CS}$

24 female patients with depression and $24 \mathrm{CS}$

44 elderly patients with MD psychotic)

44 elderly MD patients. Response to antidepressant was assessed prospectively

66 geriatric depressed patients and 18 elderly CS

17 patients with first-episode mania and $16 \mathrm{CS}$
10 depressed patients and 10 (34 nonpsychotic, 10

Measurement Major Finding

Caudate and lenticular nucleus gray matter

Ventricle size, cortical atrophy, hyperintensities

Sylvian fissures, temporal sulci, temporal horns third ventricle, lateral ventricles, cerebral sulci, periventricular and deep white matter changes

Temporal lobes, superior temporal gyrus, hemispheres, lateral ventricles, temporal horns third ventricles

Pituitary volume

Frontosubcortical volume

Morphology of posterior fossa: medulla, pons, midbrain, anterior and posterior cerebellar vermis, fourth ventricle

Gray matter

HIP volume

Volume of total amygdala and core amygdala nuclei

HIP volume

Whole brain, lateral and third ventricles, frontal lobe, parietal lobe, temporal lobe, brain stem, subcortical hyperintensities

Frontal, temporal, parietal lobes, lateral ventricles

\section{HIP volume}

Cerebral hemispheres, lateral and third ventricles, caudate, thalamus, and cingulate gyrus
Overall, no difference between depressed patients and CS, but caudate nucleusgray matter volume and severity of depression were inversely correlated

Depressed patients had increased cortical atrophy, larger ventricles, and more subcortical hyperintensities

Patients with BP and UP disorder had greater left sylvian fissure and left and right temporal sulcal enlargements, and more bilateral cortical atrophy than CS

Both patient groups had significantly larger temporal horn volumes compared with CS

BD patients had smaller pituitary volumes than CS and UP patients

Manic patients had smaller prefrontal cortical volume than CS

Patients had smaller brain stem, and anterior and posterior cerebellar vermis

Chronic depression patients showed reduced gray matter density in the left temporal cortex including the hippocampus

Depressed patients had significantly smaller left and right HIP volumes

Depressed patients had bilaterally reduced amygdala core nuclei volumes but no significant difference in total amygdala volumes

Depressed patients had smaller HIP volumes bilaterally than CS. HIP volume related to duration of depression

Psychotic patients had more brain stem, frontotemporal atrophy and marked enlargement of the third ventricle compared with nonpsychotic patients

Trend for smaller fronto-temporal volumes in treatment-resistant patients. Ventricular enlargement associated with prior use of ECT and later age at onset of depression. Reduced frontal and parietal lobe volume associated with impaired immediate working memory.

Elderly depressed patients had smaller right HIP volume

Patients with first-episode mania had significantly larger third ventricular volumes, possibly increased lateral ventricular volumes, and differences in gray/white matter distribution compared with CS 


\section{Appendix 1. Continued}

\begin{tabular}{|c|c|c|c|}
\hline MRI Studies & Subjects & Measurement & Major Finding \\
\hline Strakowski et al 1999 & $\begin{array}{l}24 \text { patients with BD and mania } \\
\text { and } 22 \mathrm{CS}\end{array}$ & $\begin{array}{l}\text { Prefrontal, thalamic, HIP, } \\
\text { amygdala, pallidal and } \\
\text { striatal volumetric } \\
\text { measurements }\end{array}$ & $\begin{array}{l}\text { Patients with BD demonstrated a significant } \\
\text { overall difference in structural volumes } \\
\text { in these regions compared with CS }\end{array}$ \\
\hline Strakowski et al 2002 & $\begin{array}{l}35 \text { patients with BD: } 18 \text { with } \\
\text { first episode, } 17 \text { with } \\
\text { multiple episodes, } 32 \mathrm{CS}\end{array}$ & $\begin{array}{l}\text { Lateral and third ventricular } \\
\text { volumes, caudate, putamen, } \\
\text { thalamus, hippocampus }\end{array}$ & $\begin{array}{l}\text { Larger lateral ventricles in multiple episode } \\
\text { than in the first episode of BD patients } \\
\text { or CS, associated with higher number of } \\
\text { prior manic episodes. Multiple episode } \\
\text { patients had smaller total cerebral } \\
\text { volume than CS but not first-episode } \\
\text { patients. }\end{array}$ \\
\hline Swayze et al 1992 & $\begin{array}{l}\text { 58 SZ and } 48 \text { BD patients, } 47 \\
\text { CS }\end{array}$ & $\begin{array}{l}\text { Putamen, caudate, temporal } \\
\text { lobe, hippocampus, } \\
\text { amygdala }\end{array}$ & $\begin{array}{l}\text { Smaller right hippocampus in BD patients } \\
\text { vs. CS }\end{array}$ \\
\hline Vakili et al 2000 & $\begin{array}{l}38 \text { patients with MD and } 20 \\
\text { CS }\end{array}$ & HIP volume & $\begin{array}{l}\text { No differences between patients and CS. } \\
\text { Negative correlation between left HIP } \\
\text { volume and baseline score of depression } \\
\text { in men. Responder women had higher } \\
\text { right HIP volume than nonresponders }\end{array}$ \\
\hline Velakoulis et al 1999 & $\begin{array}{l}46 \text { patients with chronic SZ, } \\
32 \text { patients with first- } \\
\text { episode psychosis, } 140 \mathrm{CS}\end{array}$ & HIP and whole brain volumes & $\begin{array}{l}\text { Patients with first-episode } \\
\text { SZ/schizophreniform or affective } \\
\text { psychosis both had significantly smaller } \\
\text { left HIP volumes compared with CS }\end{array}$ \\
\hline Zipursky et al 1997 & $\begin{array}{l}23 \text { patients with SZ, } 14 \\
\text { patients with BD disorder, } \\
17 \mathrm{CS}\end{array}$ & $\begin{array}{l}\text { Quantitative measures of CSF, } \\
\text { gray matter, and white } \\
\text { matter volumes }\end{array}$ & BD patients had larger ventricles than CS \\
\hline
\end{tabular}

${ }^{a}$ Note that this table lists the studies that have demonstrated changes suggestive of cell loss/atrophy; negative studies have not been included in this table.

CT, computed tomography; MRI, magnetic resonance imaging; VBR, ventricle brain ratio; CSF, cerebrospinal fluid; MDD, major depressive disorder; BPI, Bipolar disorder type I; BPII, bipolar disorder type II; BD, bipolar disorder; CS, control subjects; DAT, dementia of the Alzheimer's type; ECT, electroconvulsive therapy; HIP, hippocampal; MD, major depression; MZ, monozygotic; SZ, schixophrenia; UP, unipolar. Modified and reproduced with permission from Manji and Duman 2001.

\section{Appendix References}

Ali SO, Denicoff KD, Altshuler LL, Hauser P, Li X, Conrad AJ, et al (2001): Relationship between prior course of illness and neuroanatomic structures in bipolar disorder: A preliminary study. Neuropsychiatry Neuropsychol Behav Neurol 14:227-232.

Altshuler LL, Conrad A, Hauser P, Li XM, Guze BH, Denikoff K, et al (1991): Reduction of temporal lobe volume in bipolar disorder: A preliminary report of magnetic resonance imaging. Arch Gen Psychiatry 48:482-483.

Andreasen NC, Swayze V 2nd, Flaum M, Alliger R, Cohen G (1990): Ventricular abnormalities in affective disorder: Clinical and demographic correlates. Am J Psychiatry 147:893-900.

Ashtari M, Greenwald BS, Kramer-Ginsberg E, Hu J, Wu H, Patel M, et al (1999): Hippocampal/amygdala volumes in geriatric depression. Psychol Med 29:629-638.

Bakshi R, Czarnecki D, Shaikh ZA, Priore RL, Janardhan V, Kaliszky Z, et al (2000): Brain MRI lesions and atrophy are related to depression in multiple sclerosis. Neuroreport 11:1153-1158.

Baumann B, Bornschlegl C, Krell D, Bogerts B (1997): Changes in CSF spaces differ in endogenous and neurotic depression. A planimetric CT scan study. J Affect Disord 45:179-188.

Beats B, Levy R, Forstl H (1991): Ventricular enlargement and caudate hyperdensity in elderly depressives. Biol Psychiatry 30:452-458.

Botteron KN, Raichle ME, Drevets WC, Heath AC, Todd RD (2002): Volumetric reduction in left subgenual prefrontal cortex in early onset depression. Biol Psychiatry 51:342-344.
Brambilla P, Harenski K, Nicoletti M, Mallinger AG, Frank E, Kupfer DJ, et al (2001a): Differential effects of age on brain gray matter in bipolar patients and healthy individuals. Neuropsychobiology 43:242-247.

Brambilla P, Harenski K, Nicoletti M, Mallinger AG, Frank E, Kupfer DJ, et al (2001b): MRI study of posterior fossa structures and brain ventricles in bipolar patients. J Psychiatr Res 35:313-322.

Bremner J, Vythilingam M, Vermetten E, Nazeer A, Adil J, Khan S, et al (2002): Reduced volume of orbitofrontal cortex in major depression. Biol Psychiatry 15:273-279.

Bremner JD, Narayan M, Anderson ER, Staib LH, Miller HL, Charney DS (2000): Hippocampal volume reduction in major depression. Am J Psychiatry 157:115-118.

Coffey CE, Wilkinson WE, Weiner RD, Parashos IA, Djang WT, Webb MC, et al (1993): Quantitative cerebral anatomy in depression. A controlled magnetic resonance imaging study. Arch Gen Psychiatry 50:7-16.

Coffman JA, Bornstein RA, Olson SC, Schwarzkopf SB, Nasrallah HA (1990): Cognitive impairment and cerebral structure by MRI in bipolar disorder. Biol Psychiatry 27:1188-1196.

Dahabra S, Ashton CH, Bahrainian M, Britton PG, Ferrier IN, McAllister VA, et al (1998): Structural and functional abnormalities in elderly patients clinically recovered from early- and late-onset depression. Biol Psychiatry 44:34-46.

Dasari M, Friedman L, Jesberger J, Stuve TA, Findling RL, Swales TP, et al (1999): A magnetic resonance imaging study of thalamic area in 
adolescent patients with either schizophrenia or bipolar disorder as compared to healthy controls. Psychiatry Res 91:155-162.

DelBello MP, Strakowski SM, Zimmerman ME, Hawkins JM, Sax KW (1999): MRI analysis of the cerebellum in bipolar disorder: A pilot study. Neuropsychopharmacology 21:63-68.

Dewan MJ, Haldipur CV, Lane EE, Ispahani A, Boucher MF, Major LF (1988): Bipolar affective disorder. I. Comprehensive quantitative computed tomography. Acta Psychiatr Scand 77:670-676.

Dolan RJ, Calloway SP, Thacker PF, Mann AH (1986): The cerebral cortical appearance in depressed subjects. Psychol Med 16:775-779.

Drevets WC, Price JL, Simpson JR Jr, Todd RD, Reich T, Vannier M, et al (1997): Subgenual prefrontal cortex abnormalities in mood disorders. Nature 386:824-827.

Friedman L, Findling RL, Kenny JT, Swales TP, Stuve TA, Jesberger JA, et al (1999): An MRI study of adolescent patients with either schizophrenia or bipolar disorder as compared to healthy control subjects. Biol Psychiatry 46:78-88.

Frodl T, Meisenzahl E, Zetzsche T, Bottlender R, Born C, Groll C, et al (2002a): Enlargement of the amygdala in patients with a first episode of major depression. Biol Psychiatry 51:708-714.

Frodl T, Meisenzahl EM, Zetzsche T, Born C, Groll C, Jager M, et al (2002b): Hippocampal changes in patients with a first episode of major depression. Am J Psychiatry 159:1112-1118.

Hauser P, Altshuler LL, Berrettini W, Dauphinais ID, Gelernter J, Post RM (1989): Temporal lobe measurement in primary affective disorder by magnetic resonance imaging. J Neuropsychiatry Clin Neurosci $1: 128-134$

Hauser P, Matochik J, Altshuler LL, Denicoff KD, Conrad A, Li X, et al (2000): MRI-based measurements of temporal lobe and ventricular structures in patients with bipolar I and bipolar II disorders. $J$ Affect Disord 60:25-32.

Hirayasu Y, Shenton ME, Salisbury DF, Kwon JS, Wible CG, Fischer IA, et al (1999): Subgenual cingulate cortex volume in first-episode psychosis. Am J Psychiatry 156:1091-1093.

Husain MM, McDonald WM, Doraiswamy PM, Figiel GS, Na C, Escalona PR, et al (1991): A magnetic resonance imaging study of putamen nuclei in major depression. Psychiatry Res 40:95-99.

Johnstone EC, Owens DG, Crow TJ, Colter N, Lawton CA, Jagoe R, et al (1986): Hypothyroidism as a correlate of lateral ventricular enlargement in manic-depressive and neurotic illness. Br J Psychiatry 148:317-321.

Kato T, Shioiri T, Murashita J, Hamakawa H, Inubushi T, Takahashi S (1994): Phosphorus-31 magnetic resonance spectroscopy and ventricular enlargement in bipolar disorder. Psychiatry Res 55:41-50.

Krishnan KR, McDonald WM, Escalona PR, Doraiswamy PM, Na C, Husain MM, et al (1992): Magnetic resonance imaging of the caudate nuclei in depression. Preliminary observations. Arch Gen Psychiatry 49:553-557.

Kumar A, Bilker W, Jin Z, Udupa J (2000): Atrophy and high intensity lesions: Complementary neurobiological mechanisms in late-life major depression. Neuropsychopharmacology 22:264-274.

Kumar A, Jin Z, Bilker W, Udupa J, Gottlieb G (1998): Late-onset minor and major depression: Early evidence for common neuroanatomical substrates detected by using MRI. Proc Natl Acad Sci U S A 95:7654-7658.

Kumar A, Miller D, Ewbank D, Yousem D, Newberg A, Samuels S, et al (1997): Quantitative anatomic measures and comorbid medical illness in late-life major depression. Am J Geriatr Psychiatry 5:1525 .

Lai T, Payne ME, Byrum CE, Steffens DC, Krishnan KR (2000): Reduction of orbital frontal cortex volume in geriatric depression. Biol Psychiatry 48:971-975.

Lim KO, Rosenbloom MJ, Faustman WO, Sullivan EV, Pfefferbaum A (1999): Cortical gray matter deficit in patients with bipolar disorder. Schizophr Res 40:219-227.

Mervaala E, Fohr J, Kononen M, Valkonen-Korhonen M, Vainio P, Partanen K, et al (2000): Quantitative MRI of the hippocampus and amygdala in severe depression. Psychol Med 30:117-125.

Nasrallah HA, McCalley-Whitters M, Jacoby CG (1982): Cortical atrophy in schizophrenia and mania: A comparative CT study. J Clin Psychiatry 43:439-441.

Noga JT, Vladar K, Torrey EF (2001): A volumetric magnetic resonance imaging study of monozygotic twins discordant for bipolar disorder. Psychiatry Res 106:25-34.

Pantel J, Schroder J, Essig M, Popp D, Dech H, Knopp MV, et al (1997): Quantitative magnetic resonance imaging in geriatric depression and primary degenerative dementia. J Affect Disord 42:69-83.

Parashos IA, Tupler LA, Blitchington T, Krishnan KR (1998): Magneticresonance morphometry in patients with major depression. Psychiatry Res 84:7-15.

Pearlson GD, Garbacz DJ, Tompkins RH, Ahn HS, Gutterman DF, Veroff AE, et al (1984): Clinical correlates of lateral ventricular enlargement in bipolar affective disorder. Am J Psychiatry 141:253256.

Pearlson GD, Rabins PV, Kim WS, Speedie LJ, Moberg PJ, Burns A, et al (1989): Structural brain CT changes and cognitive deficits in elderly depressives with and without reversible dementia ("pseudodementia'). Psychol Med 19:573-584.

Pearlson GD, Veroff AE (1981): Computerised tomographic scan changes in manic-depressive illness. Lancet 2:470.

Pillay SS, Renshaw PF, Bonello CM, Lafer BC, Fava M, Yurgelun-Todd D (1998): A quantitative magnetic resonance imaging study of caudate and lenticular nucleus gray matter volume in primary unipolar major depression: Relationship to treatment response and clinical severity. Psychiatry Res 84:61-74.

Rabins PV, Aylward E, Holroyd S, Pearlson G (2000): MRI findings differentiate between late-onset schizophrenia and late-life mood disorder. Int J Geriatr Psychiatry 15:954-960.

Rabins PV, Pearlson GD, Aylward E, Kumar AJ, Dowell K (1991): Cortical magnetic resonance imaging changes in elderly inpatients with major depression. Am J Psychiatry 148:617-620.

Roy P, Zipursky R, Saint-Cyr J, Bury A, Langevin R, Seeman M (1998): Temporal horn enlargement is present in schizophrenia and bipolar disorder. Biol Psychiatry 15:418-422.

Sassi RB, Nicoletti M, Brambilla P, Harenski K, Mallinger AG, Frank E, et al (2001): Decreased pituitary volume in patients with bipolar disorder. Biol Psychiatry 50:271-280.

Sax KW, Strakowski SM, Zimmerman ME, DelBello MP, Keck PE Jr, Hawkins JM (1999): Frontosubcortical neuroanatomy and the continuous performance test in mania. Am J Psychiatry 156:139-141.

Schlegel S, Kretzschmar K (1987): Computed tomography in affective disorders. Part II. Brain density. Biol Psychiatry 22:15-23.

Shah PJ, Ebmeier KP, Glabus MF, Goodwin GM (1998): Cortical grey matter reductions associated with treatment-resistant chronic unipolar 
depression. Controlled magnetic resonance imaging study. $\mathrm{Br} J$ Psychiatry 172:527-532.

Shah SA, Doraiswamy PM, Husain MM, Escalona PR, Na C, Figiel GS, et al (1992): Posterior fossa abnormalities in major depression: A controlled magnetic resonance imaging study. Acta Psychiatr Scand $85: 474-479$.

Sheline YI, Gado MH, Price JL (1998): Amygdala core nuclei volumes are decreased in recurrent major depression. Neuroreport 9:20232028.

Sheline YI, Sanghavi M, Mintun MA, Gado MH (1999): Depression duration but not age predicts hippocampal volume loss in medically healthy women with recurrent major depression. $J$ Neurosci 19:5034-5043

Sheline YI, Wang PW, Gado MH, Csernansky JG, Vannier MW (1996): Hippocampal atrophy in recurrent major depression. Proc Natl Acad Sci U S A 93:3908-3913.

Shima S, Shikano T, Kitamura T, Masuda Y, Tsukumo T, Kanba S, et al (1984): Depression and ventricular enlargement. Acta Psychiatr Scand 70:275-277.

Shiraishi H, Koizumi J, Hori M, Terashima Y, Suzuki T, Saito K, et al (1992): A computerized tomographic study in patients with delusional and non-delusional depression. Jpn J Psychiatry Neurol 46:99-105.

Simpson S, Baldwin RC, Jackson A, Burns A (1999): The differentiation of DSM-III-R psychotic depression in later life from nonpsychotic depression: Comparisons of brain changes measured by multispectral analysis of magnetic resonance brain images, neuropsychological findings, and clinical features. Biol Psychiatry 45:193-204.

Simpson SW, Baldwin RC, Burns A, Jackson A (2001): Regional cerebral volume measurements in late-life depression: Relationship to clinical correlates, neuropsychological impairment and response to treatment. Int J Geriatr Psychiatry 16:469-476.

Steffens DC, Byrum CE, McQuoid DR, Greenberg DL, Payne ME, Blitchington TF, et al (2000): Hippocampal volume in geriatric depression. Biol Psychiatry 48:301-309.

Strakowski SM, Adler CM, DelBello MP (2002): Volumetric MRI studies of mood disorders: Do they distinguish unipolar and bipolar disorder? Bipolar Disord 4:80-88.
Strakowski SM, DelBello MP, Sax KW, Zimmerman ME, Shear PK, Hawkins JM, et al (1999): Brain magnetic resonance imaging of structural abnormalities in bipolar disorder. Arch Gen Psychiatry $56: 254-260$

Strakowski SM, Wilson DR, Tohen M, Woods BT, Douglass AW, Stoll AL (1993): Structural brain abnormalities in first-episode mania. Biol Psychiatry 33:602-609.

Swayze VW 2nd, Andreasen NC, Alliger RJ, Ehrhardt JC, Yuh WT (1990): Structural brain abnormalities in bipolar affective disorder. Ventricular enlargement and focal signal hyperintensities. Arch Gen Psychiatry 47:1054-1059.

Swayze VW 2nd, Andreasen NC, Alliger RJ, Yuh WT, Ehrhardt JC (1992): Subcortical and temporal structures in affective disorder and schizophrenia: A magnetic resonance imaging study. Biol Psychiatry $31: 221-240$.

Tanaka Y, Hazama H, Fukuhara T, Tsutsui T (1982): Computerized tomography of the brain in manic-depressive patients-a controlled study. Folia Psychiatr Neurol Jpn 36:137-143.

Vakili K, Pillay SS, Lafer B, Fava M, Renshaw PF, Bonello-Cintron CM, et al (2000): Hippocampal volume in primary unipolar major depression: A magnetic resonance imaging study. Biol Psychiatry 47:10871090.

Velakoulis D, Pantelis C, McGorry PD, Dudgeon P, Brewer W, Cook M, et al (1999): Hippocampal volume in first-episode psychoses and chronic schizophrenia: A high-resolution magnetic resonance imaging study. Arch Gen Psychiatry 56:133-141.

Weinberger DR, DeLisi LE, Perman GP, Targum S, Wyatt RJ (1982): Computed tomography in schizophreniform disorder and other acute psychiatric disorders. Arch Gen Psychiatry 39:778-783.

Wurthmann C, Bogerts B, Falkai P (1995): Brain morphology assessed by computed tomography in patients with geriatric depression, patients with degenerative dementia, and normal control subjects. Psychiatry Res 61:103-111.

Young RC, Nambudiri DE, Jain H, de Asis JM, Alexopoulos GS (1999): Brain computed tomography in geriatric manic disorder. Biol Psychiatry 45:1063-1065.

Zipursky RB, Seeman MV, Bury A, Langevin R, Wortzman G, Katz R (1997): Deficits in gray matter volume are present in schizophrenia but not bipolar disorder. Schizophr Res 26:85-92. 